\title{
Photocatalytic Water Splitting Cycle in a Dye-Catalyst Supramolecular Complex: Ab Initio Molecular Dynamics Simulations
}

\author{
Yang Shao, Jessica M. de Ruiter, ${ }^{(0)}$ Huub J. M. de Groot, and Francesco Buda*(i) \\ Leiden Institute of Chemistry, Leiden University, Einsteinweg 55, 2300 RA Leiden, The Netherlands
}

Supporting Information

\begin{abstract}
A dye-sensitized photoelectrochemical cell (DS-PEC) is a promising device for direct conversion of solar energy into fuel. The basic idea, inspired by natural photosynthesis, is to couple the photoinduced charge separation process to catalytic water splitting. The photo-oxidized dye coupled to a water oxidation catalyst (WOC) should exert a thermodynamic driving force for the catalytic cycle, while water provides the electrons for regenerating the oxidized dye. These conditions impose specific energetic constraints on the molecular components of the photoanode in the DS-PEC. Here, we consider a supramolecular complex integrating a mononuclear Ru-based WOC with a fully organic naphthalene-diimide (NDI) dye that is able to perform fast photo-

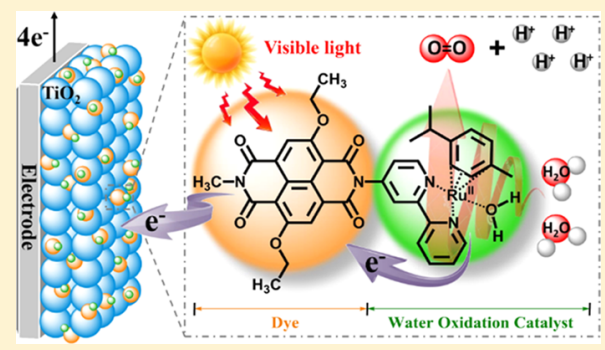
induced electron injection into the conduction band of the titanium-dioxide semiconductor anode. By means of constrained $\mathrm{ab}$ initio molecular dynamics simulations in explicit water solvent, it is shown that the oxidized NDI provides enough driving force for the whole photocatalytic water splitting cycle. The results provide strong evidence for the significant role of spin alignment and solvent rearrangement in facilitating the proton-coupled electron transfer processes. The predicted activation free energy barriers confirm that the $\mathrm{O}-\mathrm{O}$ bond formation is the rate-limiting step. Our results expand the current understanding of the photocatalytic water oxidation mechanism and provide guidelines for the optimization of high-performance DS-PEC devices.
\end{abstract}

\section{INTRODUCTION}

As the largest exploitable renewable energy source by far, solar energy has the potential to be an alternative to fossil fuelderived energy and to reduce environmental pollution. ${ }^{1,2}$ The direct conversion of solar energy to storable chemical fuel is a promising strategy for providing a sustainable source of clean energy. ${ }^{3,4}$ Inspired by natural photosynthesis and the successful photocatalytic water oxidation achieved in photosystem II (PSII), remarkable effort has been devoted to the development of efficient artificial photosynthesis devices for solar-to-fuel conversion. $^{5-12}$ A photoelectrochemical cell (PEC) performs this task by splitting water molecules into $\mathrm{O}_{2}$, protons, and electrons at the anode and evolving energy-rich $\mathrm{H}_{2}$ or $\mathrm{CO}_{2}$ derivatives at the cathode. ${ }^{13-15}$ The water oxidation halfreaction is currently considered the most challenging and limiting step for the development of efficient PEC devices for the production of solar fuels. ${ }^{16-18}$

In the past few decades, several systems have been proposed to facilitate the photocatalytic four-electron oxidation of water. ${ }^{19,20}$ In a dye-sensitized PEC (DS-PEC), the photoanode combines visible light-absorbing photosensitizers for light harvesting and charge separation and a water oxidation catalyst (WOC) for water splitting. ${ }^{21-25}$ The way these components are assembled will determine the efficiency and photostability of the device. ${ }^{25}$ Much effort has been devoted to the exploration of assembling strategies: among others, the codeposition method where the photosensitizer and the WOC are deposited as separate moieties on the semiconductor surface and the supramolecular approach where the dye and
WOC are covalently bound forming a complex anchored onto the semiconductor surface. ${ }^{17,19}$ The performance of a dyesensitized photoanode can be improved by a proper choice of the components in the WOC-dye supramolecular complex taking into account the energetics and light-absorbing properties of photosensitizers and WOCs. ${ }^{26-32}$ It is also challenging to find an ideal dye that can absorb a significant region of the visible spectrum and have at the same time an appropriate redox potential to drive the whole catalytic water oxidation cycle coupled with an efficient WOC. ${ }^{25}$ Computational studies constitute a very useful tool complementary to experiment by predicting reaction mechanisms and electronic properties of dye-sensitized photoanodes, thus avoiding an expensive trial and error strategy and providing a clear indication on the most cost-effective direction to undertake. $^{33-38}$

We recently investigated in silico a supramolecular complex $\left[(\mathrm{cy}) \mathrm{Ru}^{\mathrm{II}} \text { bpy }\left(\mathrm{H}_{2} \mathrm{O}\right)\right]^{2+}-\mathrm{NDI}\left(\mathrm{cy}=p\right.$-cymene, bpy $=2,2^{\prime}$ bipyridine, NDI = 2,6-diethoxy-1,4,5,8-diimide-naphthalene; ${ }^{1}\left(\left[\mathrm{Ru}^{\mathrm{II}}-\mathrm{OH}_{2}\right]^{2+}-\mathrm{NDI}\right)$ in Scheme 1$)$ anchored on a $\mathrm{TiO}_{2}$ semiconductor surface. ${ }^{39}$ The catalytic cycle of the mononuclear WOC $\left[(\mathrm{cy}) \mathrm{Ru}^{\mathrm{II}} \text { bpy }\left(\mathrm{H}_{2} \mathrm{O}\right)\right]^{2+}$ has been systematically examined by means of a combination of theoretical and experimental techniques ${ }^{44}$ and consists of four proton-coupled electron transfer (PCET) steps. ${ }^{40-43}$ The free energy change

Received: July 5, 2019

Revised: July 22, 2019

Published: August 7, 2019 
Scheme 1. Proposed Photocatalytic Water Splitting Cycle by a Ru-Based WOC-Dye System, Consisting of Four Catalytic Steps ${ }^{a, b, c, d, e, f, g, h, i}$

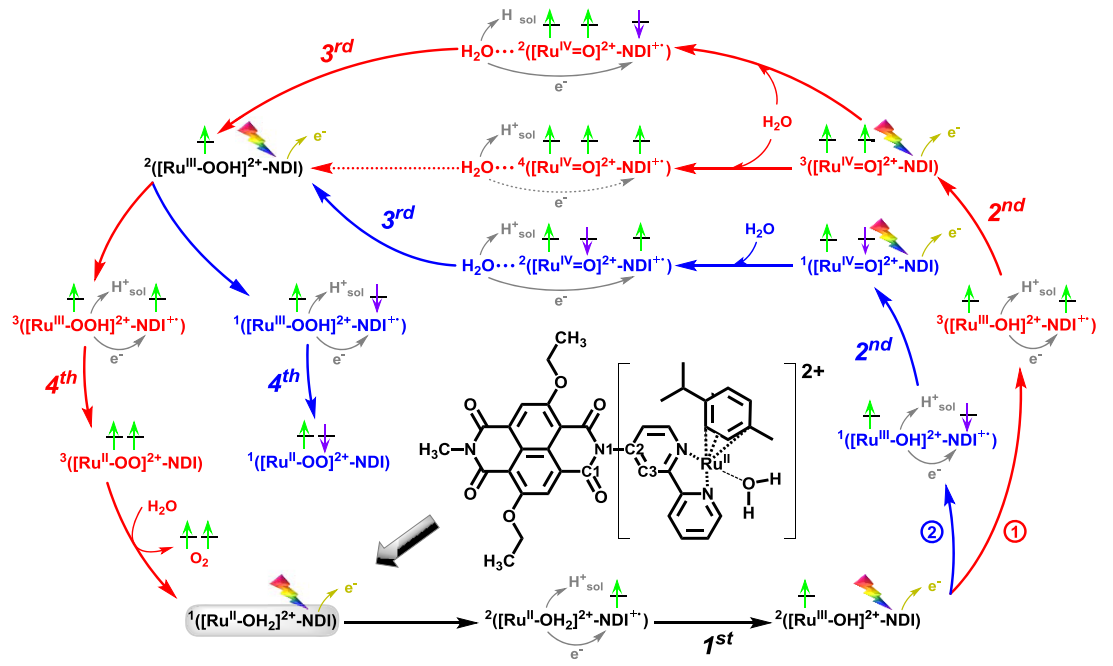

${ }^{a}$ The cycle starts from the $\left[(\mathrm{cy}) \mathrm{Ru}^{\mathrm{II}} \mathrm{bpy}\left(\mathrm{H}_{2} \mathrm{O}\right)\right]^{2+}-\mathrm{NDI}$ intermediate (indicated shortly as ${ }^{1}\left(\left[\mathrm{Ru}^{\mathrm{II}}-\mathrm{OH}_{2}\right]^{2+}-\mathrm{NDI}\right)$ ) on the bottom-left of the scheme. The schematic structure of this starting intermediate is shown explicitly in the inset. ${ }^{b}$ It is assumed that each light flash induces an electron injection (golden arrows) from the NDI to the semiconductor electrode or to the next stage in a tandem cell, leading to the photooxidation of NDI: $\mathrm{NDI} \rightarrow \mathrm{NDI}^{+\bullet}$. $^{c}$ Green ( $\alpha$ electrons) and purple ( $\beta$ electrons) vertical arrows depict the spin of unpaired electrons located on the WOC and NDI. ${ }^{d}$ For each catalytic step, we consider all possible spin alignments between unpaired electrons on the WOC and on the $\mathrm{NDI}^{+\bullet}$, resulting in two alternative routes: (1) in red and (2) in blue. ${ }^{e}$ For the first step (in black), only the doublet state is possible. ${ }^{f}$ The dashed arrow indicates a process that is found to be thermodynamically unfavorable. ${ }^{g} \mathrm{H}_{\text {sol }}^{+}$represents the proton transferred to the solvent. ${ }^{h}$ The outermost pathway is the most favorable according to the simulations. ${ }^{i}$ The superscript on the left indicates the spin multiplicity $2 S+1$ for each intermediate.

of this WOC for each catalytic step from the initial intermediate $I_{1}$ to the final intermediate $I_{0}$ is reported in Table S1 and Figure S1 in the Supporting Information (SI). ${ }^{44}$ The NDI chromophore family has shown good optical performance in photovoltaics, artificial photosystems, and allpolymer solar cells and potential in achieving photoinduced long-distance charge separation and reducing charge recombination. ${ }^{45-50}$ In a recent computational work, it has been shown that the NDI dye with diethoxy functional groups considered in this work performs fast electron injection in the $\mathrm{TiO}_{2}$ semiconductor conduction band on a ps time scale. ${ }^{39}$ Furthermore, a very low activation barrier was estimated for the first water oxidation catalytic step upon photooxidation of the molecular photosensitizer $\left(\mathrm{NDI}^{+\bullet}\right)$ covalently bound to the Ru-based WOC. ${ }^{39}$ The choice of anchoring groups with established chemical and thermal stabilities, ${ }^{51-53}$ the inclusion of bridge units with rectifying properties, ${ }^{54}$ and ancillary chromophores with complementary absorption properties and redox potentials ${ }^{55}$ can contribute to the optimization of the photoanode design.

The role of the oxidized dye in this WOC-dye supramolecular complex is analogous to that of the redox-active tyrosine (Tyr-161) near the oxygen evolving complex in PSII, in stabilizing the hole and acting as a primary electron acceptor during the catalytic water oxidation cycle. ${ }^{8}$ In this work, we focus on the coupling between the catalyst and the dye and the ability of this photo-oxidized NDI dye to drive the whole water splitting cycle. By using static density functional theory (DFT) calculations, we first ascertain whether the NDI dye considered in this work has the basic energetic requirements, that is, enough oxidation power, to drive the whole catalytic cycle for water oxidation $^{25}$ (see the schematic energy diagram in Figure S2). Moreover, by means of constrained ab initio molecular dynamics (AIMD) simulations in an explicit water solvent, we establish the free energy profile for all of the catalytic reaction steps starting from the oxidized WOC-dye intermediates (Scheme 1). This allows one also to determine the activation energy $\Delta G^{*}$ that can be used to estimate the reaction rate. The effect of spin alignment between unpaired electrons on the WOC and on the $\mathrm{NDI}^{+} \bullet$ is also explored (see routes (1) and (2) in Scheme 1). In particular, for the second step starting from the oxidized WOC-dye intermediates ${ }^{1}\left(\left[\mathrm{Ru}^{\mathrm{III}}-\mathrm{OH}\right]^{2+}-\right.$ $\left.\mathrm{NDI}^{+\bullet}\right)$ (route (2) and ${ }^{3}\left(\left[\mathrm{Ru}^{\mathrm{III}}-\mathrm{OH}\right]^{2+}-\mathrm{NDI}^{+\bullet}\right)$ (route (1) are considered, for the third step the intermediates ${ }^{2}\left(\left[\mathrm{Ru}^{\mathrm{IV}}=\right.\right.$ $\left.\mathrm{O}^{2+}-\mathrm{NDI}^{+\bullet}\right)$ and ${ }^{4}\left(\left[\mathrm{Ru}^{\mathrm{IV}}=\mathrm{O}\right]^{2+}-\mathrm{NDI}^{+\bullet}\right)$ are considered, and for the fourth step the intermediates ${ }^{1}\left(\left[\mathrm{Ru}^{\mathrm{III}}-\mathrm{OOH}\right]^{2+}-\right.$ $\left.\mathrm{NDI}^{+\bullet}\right)$ and ${ }^{3}\left(\left[\mathrm{Ru}^{\mathrm{III}}-\mathrm{OOH}\right]^{2+}-\mathrm{NDI}^{+\bullet}\right)$ are considered. A negative free energy change $\Delta G^{0}$ is found for all of the consecutive PCET steps, thus indicating that the oxidized $\mathrm{NDI}^{+\bullet}$ is fit for purpose. The obtained activation free energy barriers $\Delta G^{*}$ show that the $\mathrm{O}-\mathrm{O}$ bond formation is the ratelimiting step. The AIMD simulations clarify the coupling between the electron transfer process and the bond-breaking/forming events. ${ }^{56}$ Moreover, the explicit inclusion of the solvent highlights the active role of the water rearrangement in the PCET processes. The gained insight in the photocatalytic water oxidation mechanism provides guidelines for the design and optimization of efficient photoanodes for DS-PEC devices.

\section{COMPUTATIONAL DETAILS}

2.1. Geometry Optimization at the DFT Level. The initial geometries of all of the catalytic intermediates of the WOC-dye supramolecular complex were optimized using DFT calculations employing the OPBE exchange-correlation functional $^{57}$ and the triple- $\zeta$ polarized Slater-type basis set. ${ }^{39}$ The OPBE functional was shown to be accurate in describing transition-metal complexes, including Ru-based WOCs. ${ }^{58-63}$ In Table S2 (SI), we show a comparison between OPBE 
results and those obtained with the more commonly used Perdew-Burke-Ernzerhof (PBE) functional, which provides very similar results. In the geometry optimization, the continuum solvation model $\left(\mathrm{COSMO}^{64,65}\right)$ for water was used. These static calculations are performed with the Amsterdam density functional (ADF) software package. ${ }^{66,67}$

2.2. Constrained ab Initio Molecular Dynamics. To obtain a realistic description of the catalytic reaction steps, the solvent was explicitly introduced in the simulations. ${ }^{61,68} \mathrm{An}$ orthorhombic box of dimensions $25.1 \times 17.7 \times 14.4 \AA^{3}$ was used, containing the $[\mathrm{WOC}]^{2+}-$ dye solute and 162 water molecules. The explicitly solvated systems were investigated through AIMD for the singly oxidized form of the complex $\left([\mathrm{WOC}]^{2+}-\mathrm{dye}^{+\bullet}\right)$ using the Car-Parrinello MD (CPMD) program. ${ }^{69}$ The solvent environment for the CPMD simulations (pure neutral water, no ion included) was generated using Discovery Studio 2.5. ${ }^{70}$ Prior to the AIMD simulations, the solvent was equilibrated using the TIP3P model implemented in the CHARMM force field and CFF partial charge parameters at $300 \mathrm{~K}^{71}$ while the $[\mathrm{WOC}]^{2+}$-dye complex was kept fixed. The volume was then adjusted using constant pressure, after which the system was further allowed to evolve with constant volume.

A so-called regeneration step is carried out at the beginning of each PCET step by first removing the excess solvated proton from the simulation box and performing an unconstrained $\mathrm{MD}$ simulation of $\sim 360$ fs at room temperature to equilibrate the system. Subsequently, one electron is removed from the simulation box, and the oxidized state is further re-equilibrated for another $\sim 360$ fs at room temperature.

All of the CPMD simulations were performed in an aqueous environment at $300 \mathrm{~K}$, using GTH pseudopotentials for the ruthenium transition metal ${ }^{72}$ and dispersion-corrected pseudopotentials for the remaining atoms, ${ }^{73}$ together with a plane wave cutoff of $70 \mathrm{Ry}$ and the OPBE exchange-correlation functional. The water molecules are treated at the same DFT quantum-mechanical level as the solute, which is essential for the accurate description of the PCET steps following photoinduced electron injection from the NDI dye into the semiconductor. Periodic boundary conditions $(\mathrm{pbc})$ are applied. The effect of pbc for charged systems can be important when dealing with isolated molecules/clusters in the simulation box. However, because of the quite large simulation box used and the screening due to the explicit water molecules, the spurious effect of periodic charges is estimated to be rather small $(\sim 0.01 \mathrm{eV})$. The time step in the CPMD simulations is $\delta \mathrm{t}=5 \mathrm{au}(1 \mathrm{au}=0.0242 \mathrm{fs})$. Trajectory analysis and visualization for the CPMD output were carried out using VMD. ${ }^{74,75}$

Given that the catalytic reaction steps are unlikely to occur spontaneously during the typical AIMD simulation time scale, constrained MD and the so-called Blue-Moon approach were employed as a rare event simulation technique. ${ }^{76-78}$ The reaction coordinate (in this case the distance between two atoms shown in Scheme 2) is constrained to a series of fixed values along a reaction path for both routes (1) and (2):

(i) for the second PCET step (Scheme 1), the distance between the proton $\left(\mathrm{H}_{\mathrm{i}}\right)$ of the hydroxide ligand coordinated to the $\mathrm{Ru}$ atom and the oxygen $\left(\mathrm{O}_{\mathrm{ii}}\right)$ of one solvent water molecule in the vicinity of ${ }^{2}\left(\left[\mathrm{Ru}^{\mathrm{III}}-\right.\right.$ $\mathrm{OH}]^{2+}$ ) is constrained in the range 1.6-1.0 $\AA$ (Scheme 2a);
Scheme 2. Schematic Structure of the Hydroxide (a), Oxo (b), and Hydroperoxide Ligand (c) with a Nearby Solvent Water Molecule ${ }^{a, b}$

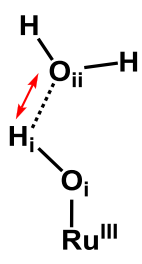

(a)

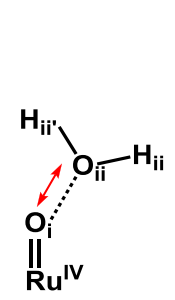

(b)

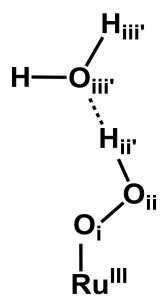

(c)
${ }^{a}$ The red double-sided arrow indicates the reaction coordinate considered for the (a) $\left[\mathrm{Ru}^{\mathrm{III}}-\mathrm{OH}\right]^{2+} \ldots \mathrm{H}_{2} \mathrm{O}$ and (b) $\left[\mathrm{Ru}^{\mathrm{IV}}=\mathrm{O}\right]^{2+} \ldots$ $\mathrm{H}_{2} \mathrm{O}$ during the constrained MD simulations. ${ }^{b}$ The labeling of the atoms that are involved in the reaction steps is used throughout this paper.

(ii) for the third PCET step, the distance between the oxygen $\left(\mathrm{O}_{\mathrm{i}}\right)$ coordinated to the $\mathrm{Ru}$ atom and the oxygen $\left(\mathrm{O}_{\mathrm{ii}}\right)$ of one solvent water molecule is constrained in the range 3.0-1.5 $\AA$ (Scheme 2b); and

(iii) for the fourth PCET step, no constraint is applied in the simulations (Scheme 2c).

For each value of the reaction coordinate $x$, a time-averaged constraint force $\langle\lambda\rangle_{x}$ is obtained. This time-averaged constraint force is equal to zero at an equilibrium or transition state. The free energy change for each catalytic step is then obtained by thermodynamic integration along the reaction path. ${ }^{56,79-81}$

\section{RESULTS AND DISCUSSION}

The whole photocatalytic water splitting cycle via both routes (1) and (2), as depicted in Scheme 1, is explored with AIMD simulations in an explicit water solvent. In a previous work, we have shown that when excited with visible light, the NDI is able to inject an electron into a $\mathrm{TiO}_{2}$ semiconductor surface in a time scale of $\sim 1$ ps. $^{39}$ Therefore, we assume that at the beginning of the simulation for each catalytic step, the system is already in its oxidized form: $[\mathrm{WOC}]^{2+}-\mathrm{dye}^{+\bullet}$.

Before starting the AIMD simulations, we have checked with static DFT calculations whether the singly occupied highest molecular orbital on the oxidized dye is lower in energy than the highest occupied orbital localized on the catalyst, since this is a basic energetic requirement to allow for electron transfer from the WOC to the dye, thus regenerating the ground state of the dye for the next photoinduced catalytic step (Figure S2 in the SI). It is found that this energy-level alignment is indeed satisfied for all of the intermediates in the catalytic cycle following route (1), which turned out to be the most favorable route: the orbital energy difference is in the range $\sim 0.1-0.3 \mathrm{eV}$ (Figure S3 and Table S2 in the SI).

Table 1 summarizes the computed activation energy barrier $\left(\Delta G^{*}\right)$, the free energy change from the initial to the final state (driving force, $\Delta G^{0}$ ), and the estimated reaction rate for the whole catalytic cycle and different spin alignments shown in Scheme 1. In the following, we discuss in detail the most favorable catalytic cycle, whereas results concerning thermodynamically unfavorable catalytic steps are reported in the SI for comparison.

We have previously shown that the first PCET catalytic step $\left(\left[\mathrm{Ru}^{\mathrm{II}}-\mathrm{OH}_{2}\right]^{2+}-\mathrm{NDI}^{+\bullet} \rightarrow\left[\mathrm{Ru}^{\mathrm{III}}-\mathrm{OH}\right]^{2+}-\mathrm{NDI}+\mathrm{H}_{\mathrm{sol}}^{+}\right)$is 
Table 1. Computed Activation Energy Barrier $\left(\Delta G^{*}, \mathrm{kcal} \mathrm{mol}^{-1}\right)$, Thermodynamic Driving Force $\left(\Delta G^{0}, \mathrm{kcal} \mathrm{mol}^{-1}\right)$, and Estimated Reaction Rate $\left(k\right.$ in $\left.\mathrm{s}^{-1}\right)$ for the Four Redox Couples along the Whole Catalytic Cycle and Different Spin Alignments along Routes (1) and (2) Shown in Scheme $1^{a, b, c, a, e}$

\begin{tabular}{|c|c|c|c|c|c|c|c|}
\hline Step & Route & $2 S+1$ & Initial state & Final state & $\Delta \mathbf{G}^{*}$ & $\Delta \mathbf{G}^{\mathbf{0}}$ & $\boldsymbol{k}$ \\
\hline $1^{\text {st }}$ & & & {$\left[\mathrm{Ru}^{\mathrm{II}}-\mathrm{OH}_{2}\right]^{2+}-\mathrm{NDI}^{+\cdot}$} & {$\left[\mathrm{Ru}{ }^{\mathrm{III}}-\mathrm{OH}\right]^{2+}-\mathrm{NDI}+\mathrm{H}_{\mathrm{sol}}^{+}$} & & & \\
\hline \multirow{4}{*}{$2^{\text {nd }}$} & (1) $+(2)$ & 2 & $\uparrow$ & $\uparrow$ & 1.7 & -4.0 & $3.6 \times 10^{11}$ \\
\hline & & & {$\left[\mathrm{Ru}^{\mathrm{III}}-\mathrm{OH}\right]^{2+}-\mathrm{NDI}^{+\bullet}$} & {$\left[\mathrm{Ru}^{\mathrm{IV}}=\mathrm{O}\right]^{2+}-\mathrm{NDI}+\mathrm{H}^{+}{ }_{\text {sol }}$} & & & \\
\hline & (1) & 3 & 平 & $\hat{\uparrow} \uparrow$ & 2.3 & -10.7 & $1.3 \times 10^{11}$ \\
\hline & (2) & 1 & $\uparrow$ & $\hat{\uparrow} \downarrow$ & 4.6 & -1.1 & $2.8 \times 10^{9}$ \\
\hline \multirow[t]{4}{*}{$3^{\text {rd }}$} & & & {$\left[\mathrm{Ru}^{\mathrm{IV}}=\mathrm{O}\right]^{2+}-\mathrm{NDI}^{+} \cdot$} & {$\left[\mathrm{Ru}{ }^{\mathrm{III}}-\mathrm{OOH}\right]^{2+}-\mathrm{NDI}+\mathrm{H}_{\mathrm{sol}}^{+}$} & & & \\
\hline & (1) & 2 & $\hat{\uparrow} \uparrow$ & $\uparrow$ & 15.9 & -8.5 & 15.7 \\
\hline & & 4 & $\uparrow \uparrow$ & & & & \\
\hline & (2) & 2 & $\hat{t} \neq$ & $\uparrow$ & 9.0 & -17.1 & $1.7 \times 10^{6}$ \\
\hline \multirow[t]{3}{*}{$4^{\text {th }}$} & & & {$\left[\mathrm{Ru}^{\mathrm{III}}-\mathrm{OOH}\right]^{2+}-\mathrm{NDI}^{+\cdot}$} & {$\left[\mathrm{Ru}^{\mathrm{II}}-\mathrm{OO}\right]^{2+}-\mathrm{NDI}+\mathrm{H}_{\text {sol }}^{+}$} & & & \\
\hline & (1) + (2) & 1 & † & & & & \\
\hline & & 3 & 斗 & $\hat{\neq} \hat{\neq}$ & & & \\
\hline
\end{tabular}

${ }^{a}$ For each intermediate, it is indicated explicitly where the unpaired electrons are localized, on the Ru-based catalyst or the NDI († for $\alpha$ electron and \pm for $\beta$ electron). ${ }^{b} 2 S+1$ is the spin multiplicity of the system, and $\mathrm{H}_{\text {sol }}^{+}$represents the solvated proton. ${ }^{c}$ For the third step, the $S=3 / 2$ state turns out to be thermodynamically unfavorable compared with the $S=1 / 2$ configuration in route (1). ${ }^{d}$ The fourth step is found to proceed spontaneously at room temperature for both spin states, which implies no significant activation barrier. ${ }^{e}$ The results for the first step are from ref 39 .

exothermic with a thermodynamic driving force $\Delta G^{0} \approx-4$

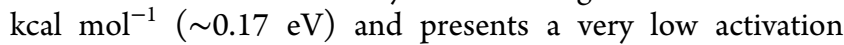
energy barrier $\Delta G^{*} \approx 1.7 \mathrm{kcal} \mathrm{mol}^{-1}(\sim 0.074 \mathrm{eV})$, which is only $\sim 3 k_{\mathrm{B}} T$ at room temperature, corresponding to a very fast rate (Table 1). ${ }^{39}$ In the following sections, the successive PCET catalytic water oxidation steps are discussed.

3.1. Second Catalytic Water Oxidation Step. The system with the oxidized intermediate ${ }^{3}\left(\left[\mathrm{Ru}^{\mathrm{III}}-\mathrm{OH}\right]^{2+}-\right.$ $\mathrm{NDI}^{+\bullet}$ ) in the $S=1$ state (see route (1) in Scheme 1) is equilibrated at room temperature without constraint for $\sim 2$ ps (Figure S4 in the Supporting Information). By tracing the spin density along the free MD simulation, we observe the photoinduced hole localized on the oxidized $\mathrm{NDI}^{+}{ }^{\bullet}$ and one unpaired electron localized on the catalyst as expected (Figure S4, inset). The analysis of the MD trajectory shows the hydroxide ligand forming a strong hydrogen bond with a nearby water molecule with an average distance $d\left(\mathrm{H}_{\mathrm{i}}-\mathrm{O}_{\mathrm{ii}}\right)$ of $\sim 1.7 \AA$ (Figure S4). Although we can observe some spontaneous attempts of proton transfer from the hydroxide to the neighboring water molecule, this process may occur on a time scale that is still prohibitive for AIMD. ${ }^{39}$ Thus, we use constrained AIMD to analyze the second PCET step shown in eq 1 , where $\mathrm{H}_{\text {sol }}^{+}$represents the solvated proton

$$
\begin{aligned}
& { }^{3}\left(\left[\mathrm{Ru}^{\mathrm{III}}-\mathrm{OH}\right]^{2+}-\mathrm{NDI}^{+\bullet}\right) \\
& \leftrightarrow^{3}\left(\left[\mathrm{Ru}^{\mathrm{IV}}=\mathrm{O}\right]^{2+}-\mathrm{NDI}\right)+\mathrm{H}_{\mathrm{sol}}^{+}
\end{aligned}
$$

Given the average $d\left(\mathrm{H}_{\mathrm{i}}-\mathrm{O}_{\mathrm{ii}}\right)$ of $\sim 1.7 \AA$ extracted from the unconstrained $\mathrm{MD}$ simulation, a series of constrained $\mathrm{MD}$ simulations are performed with $d\left(\mathrm{H}_{\mathrm{i}} \leftarrow \mathrm{O}_{\mathrm{ii}}\right)$ as the reaction coordinate (Scheme 2), which is shortened gradually from 1.6 to $1.05 \AA$ (noted in gray in Figure 1), to estimate the free energy profile along the reaction path. To test the stability of the obtained intermediate ${ }^{3}\left(\left[\mathrm{Ru}^{\mathrm{IV}}=\mathrm{O}\right]^{2+}-\mathrm{NDI}\right)$ in the catalytic cycle, we also perform a free $\mathrm{MD}$ at the end of the $1.05 \AA$ constrained simulation. The variation of the total spin density localized on the catalyst (black line), time evolution of the geometrical parameter $d\left(\mathrm{H}_{\mathrm{i}}-\mathrm{O}_{\mathrm{i}}\right)$ (magenta line), and the distance between $\mathrm{Ru}$ and $\mathrm{H}_{3} \mathrm{O}^{+}$along different constrained
MD trajectories are collected in Figure 1, top, middle, and bottom, respectively.

For the first two MD trajectories with constrained distances 1.6 and $1.4 \AA$, one unpaired electron is localized on the oxidized $\mathrm{NDI}^{+\bullet}$ dye and the other unpaired electron on the catalyst (Figure 1, inset a). The spin density initially localized on the oxidized $\mathrm{NDI}^{+}$gradually moves to the catalyst as a result of the shortening of $d\left(\mathrm{H}_{\mathrm{i}} \leftarrow \mathrm{O}_{\mathrm{ii}}\right)$ and corresponding weakening of the $\mathrm{H}_{\mathrm{i}}-\mathrm{O}_{\mathrm{i}}$ bond (Figure 1, top and middle). When $d\left(\mathrm{H}_{\mathrm{i}} \leftarrow \mathrm{O}_{\mathrm{ii}}\right)=1.2 \AA$, the $\mathrm{H}_{\mathrm{i}}$ proton is shared between the hydroxide and the attacking water molecule with an average $d\left(\mathrm{H}_{\mathrm{i}}-\mathrm{O}_{\mathrm{i}}\right)$ of $\sim 1.2 \AA$, leading to the formation of the first $\mathrm{H}_{3} \mathrm{O}^{+}$(Figure 1, bottom). Further shortening of $d\left(\mathrm{H}_{\mathrm{i}} \leftarrow\right.$ $\mathrm{O}_{\mathrm{ii}}$ ) to $1.1 \AA$ induces full transfer of an electron from the catalyst to the oxidized $\mathrm{NDI}^{+}$dye. This results in filling the hole on the $\mathrm{NDI}^{+\bullet}$ as shown in Figure 1, inset b, where no spin density is localized on the NDI. During the same constrained MD at $1.1 \AA$, we observe that the $\mathrm{H}_{\mathrm{i}}-\mathrm{O}_{\mathrm{i}}$ bond is totally broken and the generated proton diffuses from $\mathrm{O}_{\mathrm{ii}}$ of the attacking water molecule to neighboring water molecules (Figure 1, bottom). At the end of the constrained MD simulation, the $\mathrm{Ru}$ catalyst has two unpaired $\alpha$ electrons as expected on the basis of previous calculations indicating that the $\left[\mathrm{Ru}^{\mathrm{IV}}=\mathrm{O}\right]^{2+}$ intermediate has a triplet ground-state $(S=1) .{ }^{44}$ The obtained product ${ }^{3}\left(\left[\mathrm{Ru}^{\mathrm{IV}}=\mathrm{O}\right]^{2+}-\mathrm{NDI}\right)$ is verified to be stable at room temperature during the free MD simulation (FMD in Figure 1) as no proton or electron recombination is observed and the released proton diffuses through the solvent. The proton diffusion process in liquid water can be described by the Grotthuss mechanism involving covalent bond breaking and formation within the hydrogen-bonding network. ${ }^{82-89}$

The free energy profile along the reaction coordinate $d\left(\mathrm{H}_{\mathrm{i}}\right.$ $\left.\leftarrow \mathrm{O}_{\mathrm{ii}}\right)$ is estimated by numerical integration of the mean forces extracted from the constrained dynamics, ${ }^{56,81}$ and it is reported in Figure 2 (bottom). The mean force values corresponding to the applied constraints are presented in Figure 2 (top) together with the 100-point Akima spline interpolation utilized for the integration. In Figures S5 and S6 in the SI, we show that the running average of the Lagrangian 


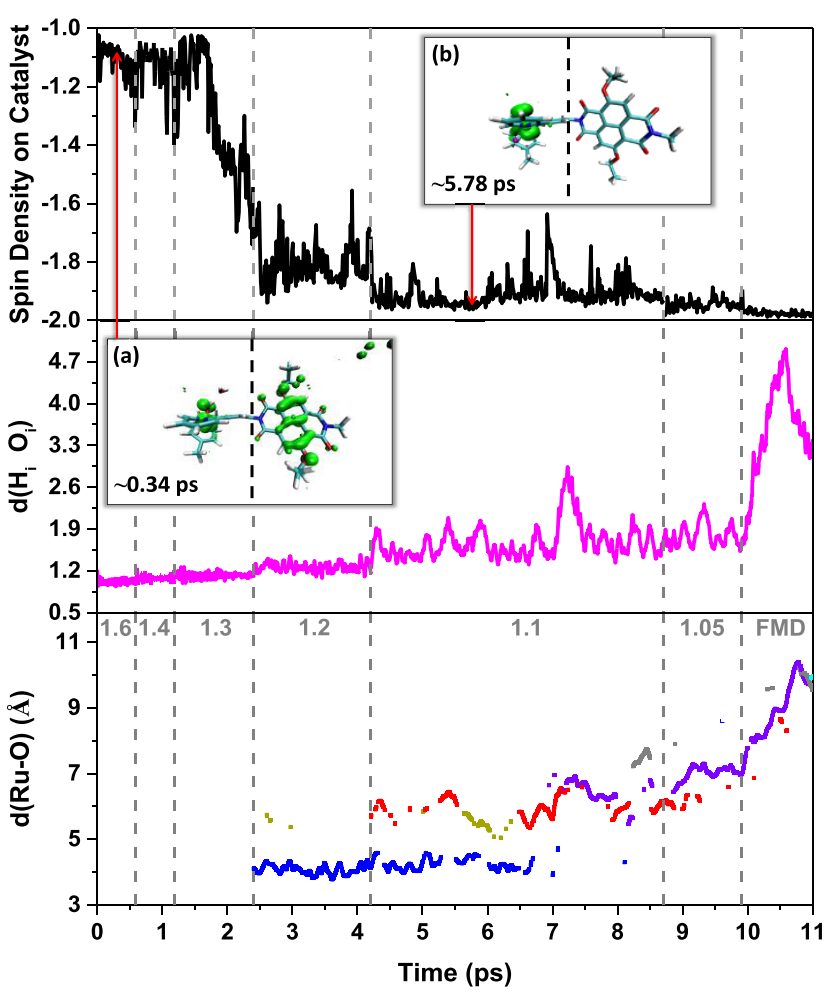

Figure 1. (Top) Spin density integrated over half of the simulation box including the catalyst (left-hand side of the dashed black line in the inset (a) and (b)) along the MD trajectories starting from the oxidized intermediate ${ }^{3}\left(\left[\mathrm{Ru}^{\mathrm{III}}-\mathrm{OH}\right]^{2+}-\mathrm{NDI}^{+\bullet}\right)$ (see route (1) in Scheme 1). An integrated spin density value of -1 corresponds to one unpaired $\alpha$ electron. The starting configuration at $d\left(\mathrm{H}_{\mathrm{i}} \leftarrow \mathrm{O}_{\mathrm{ii}}\right)=1.6 \AA$ (see Scheme 2 for the atomic labels) has been extracted from a previous unconstrained simulation of the first catalytic intermediate. (Middle) Time evolution of the geometrical parameter $d\left(\mathrm{H}_{\mathrm{i}}-\mathrm{O}_{\mathrm{i}}\right)$ (Scheme 2) along the constrained and free MD (FMD) trajectory. (Bottom) Distance between $\mathrm{Ru}$ and $\mathrm{H}_{3} \mathrm{O}^{+}$, defined as an oxygen atom with $3 \mathrm{H}$ within a radius of $1.2 \AA$, illustrating the proton diffusion during the MD simulations. The analysis of the trajectories shows that only one oxygen is in the $\mathrm{H}_{3} \mathrm{O}^{+}$form at any time, and the excess proton associates primarily to four different oxygens (indicated with different colors: blue, gold, red, and purple) during the simulation. The value of the constrained reaction coordinate $d\left(\mathrm{H}_{\mathrm{i}} \leftarrow \mathrm{O}_{\mathrm{ii}}\right)$ applied in the MD simulations is noted in gray. Inset (a) shows a snapshot from the beginning of the trajectory corresponding to a constraint value of $1.6 \AA$, where one unpaired $\alpha$ electron (green spin density isosurface) is localized on the catalyst and the other unpaired $\alpha$ electron on the $\mathrm{NDI}^{+\bullet}$; inset (b) shows a snapshot from the trajectory corresponding to a constraint value of $1.1 \AA$, where two unpaired $\alpha$ electrons are both localized on the catalyst.

multiplier reaches a stable value even within a relatively short MD time scale of $\sim 0.5$ ps. The second catalytic step shows an activation energy barrier $\Delta G^{*} \approx 2.3 \mathrm{kcal} \mathrm{mol}^{-1}(\sim 0.10 \mathrm{eV})$ that is slightly higher than in the first catalytic step (Table 1). Noticeably, a much larger driving force $\Delta G^{0} \approx-10.7 \mathrm{kcal}$ $\mathrm{mol}^{-1}(\sim 0.46 \mathrm{eV})$ is found for this step compared with the first, indicating an exothermic process after the photooxidation and a quite stable product intermediate ${ }^{3}\left(\left[\mathrm{Ru}^{\mathrm{IV}}=\mathrm{O}\right]^{2+}-\mathrm{NDI}\right)$ in the $S=1$ state. The $\mathrm{Ru}-\mathrm{O}_{\mathrm{i}}$ bond is shortened from an average length of $1.93 \AA$ to $1.76 \AA$ through this reaction, extracted from the unconstrained MD simulation before and after the second catalytic step, which contributes to the stabilization of the obtained intermediate. These findings demonstrate that the second catalytic water oxidation step in

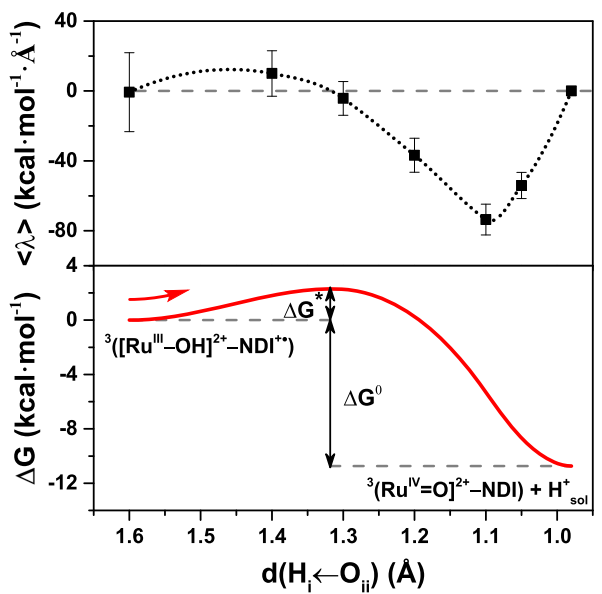

Figure 2. (Top) Constraint mean force represented by the Lagrangian multiplier $\langle\lambda\rangle$ (black squares) computed for each constrained $\mathrm{MD}$ simulation as a function of the reaction coordinate $d\left(\mathrm{H}_{\mathrm{i}} \leftarrow \mathrm{O}_{\mathrm{ii}}\right)$ along route (1) for the triplet spin state. The mean force at the equilibrium distance $d\left(\mathrm{H}_{\mathrm{i}}-\mathrm{O}_{\mathrm{ii}}\right)=0.98 \AA$ evaluated in the free MD has been set to 0 . The 100-point Akima spline interpolation (dotted line) is used to interpolate the mean forces including also the zero point at equilibrium. The error bars indicate the standard deviations. (Bottom) Free energy profile along the reaction coordinate $d\left(\mathrm{H}_{\mathrm{i}} \leftarrow\right.$ $\mathrm{O}_{\mathrm{ii}}$ ) computed from thermodynamic integration of the interpolated time-averaged mean forces. The initial and final intermediates are also indicated.

route (1) is thermodynamically favorable upon photooxidation of the dye and can indeed proceed at a high rate at room temperature given the low activation energy, similar to the first catalytic step (Table 1).

The opposite spin orientation on NDI has been also investigated, and the results are reported in the Supporting Information Figures S7-S9 and Table S3. The initial free MD equilibration for the oxidized intermediate ${ }^{1}\left(\left[\mathrm{Ru}^{\mathrm{III}}-\mathrm{OH}\right]^{2+}-\right.$ $\mathrm{NDI}^{+\bullet}$ ) in the $S=0$ state clearly shows the antiparallel spins (inset $b$ in Figure S9). Considering the relatively higher activation energy barrier and smaller driving force along route (2) compared with that of route (1) (Table 1 and Figure S7), route (2) is thermodynamically less favorable. Moreover, the product intermediate ${ }^{3}\left(\left[\mathrm{Ru}^{\mathrm{IV}}=\mathrm{O}\right]^{2+}-\mathrm{NDI}\right)$ is found to be more stable than ${ }^{1}\left(\left[\mathrm{Ru}^{\mathrm{IV}}=\mathrm{O}\right]^{2+}-\mathrm{NDI}\right)$ (Figure S8 and Table S3), confirming that route (1) is the most likely for this catalytic step.

3.2. Third Catalytic Water Oxidation Step: O-O Bond Formation. The third catalytic step involves the $\mathrm{O}-\mathrm{O}$ bond formation and is commonly found to be the most thermodynamically demanding process in catalytic water oxidation (Table S1 and Figure S1). ${ }^{34,44,90}$ To check whether the selected NDI dye is able to drive the third catalytic water oxidation step, AIMD simulations are performed for the oxidized complex $\left[\mathrm{Ru}^{\mathrm{IV}}=\mathrm{O}\right]^{2+}-\mathrm{NDI}^{+\bullet}$ in an explicit water solvent.

In the $\left[\mathrm{Ru}^{\mathrm{IV}}=\mathrm{O}\right]^{2+}-\mathrm{NDI}^{+\bullet}$ intermediate, there are two unpaired electrons localized on the catalyst and one unpaired electron on the oxidized dye. Two specific initial spin states are therefore investigated (see route (1) in Scheme 1 and Table 1):

(I) ${ }^{4}\left(\left[\mathrm{Ru}^{\mathrm{IV}}=\mathrm{O}\right]^{2+}-\mathrm{NDI}^{+\bullet}\right)(S=3 / 2)$ : two unpaired $\alpha$ electrons ( $\uparrow$ ) localized on the catalyst and one unpaired $\alpha$ electron localized on the oxidized dye; 

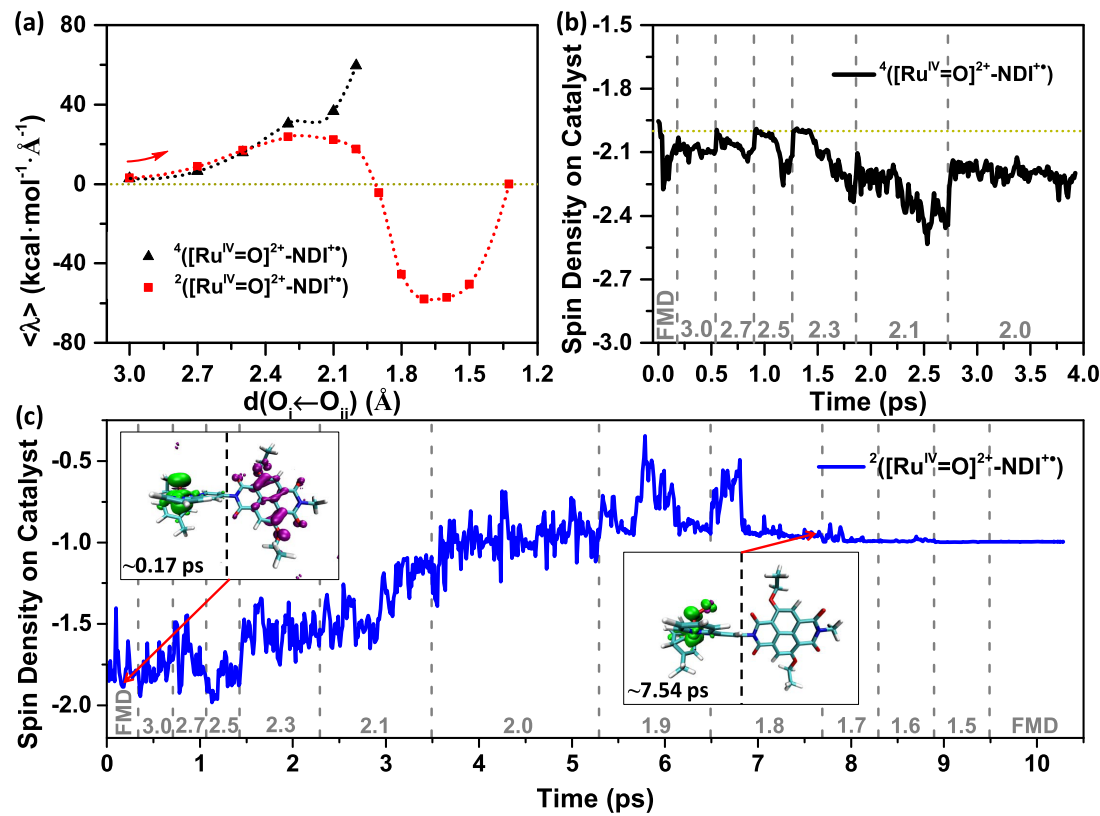

Figure 3. (a) Average constraint force represented by the Lagrangian multiplier $\langle\lambda\rangle$ computed for each constrained MD simulation with quartet multiplicity (black triangles) and doublet multiplicity (red squares) as a function of the reaction coordinate $d\left(\mathrm{O}_{\mathrm{i}} \leftarrow \mathrm{O}_{\mathrm{ii}}\right)$. The Akima spline $(100$ points) is used to interpolate the mean forces (dotted lines). The point at $d\left(\mathrm{O}_{\mathrm{i}}-\mathrm{O}_{\mathrm{ii}}\right)=1.32 \AA$ corresponds to the equilibrium product state, and thus its $\langle\lambda\rangle$ is assumed to be zero. The spin density integrated over half of the simulation box that includes the catalyst along the constrained and free MD trajectories is shown in (b) for the quartet and in (c) for the doublet state. In the panels (b) and (c), the value of the constrained reaction coordinate $d\left(\mathrm{O}_{\mathrm{i}} \leftarrow \mathrm{O}_{\mathrm{ii}}\right)$ in the MD simulations is also indicated in gray. Inset (left) shows a snapshot from the FMD trajectory, where two unpaired $\alpha$ electrons (green spin density isosurface) are localized on the catalyst and one unpaired $\beta$ electron (purple spin density isosurface) on the oxidized $\mathrm{NDI}^{+\bullet}$; inset (right) shows a snapshot from the final part of the trajectory corresponding to a constraint value of $1.8 \AA$, where only one unpaired $\alpha$ electron is left on the catalyst.

(II) ${ }^{2}\left(\left[\mathrm{Ru}^{\mathrm{IV}}=\mathrm{O}\right]^{2+}-\mathrm{NDI}^{+\bullet}\right)(S=1 / 2)$ : two unpaired $\alpha$ electrons localized on the catalyst and one unpaired $\beta$ electron (with opposite spin $\downarrow$ ) localized on the oxidized dye.

We performed constrained MD simulations for both spin states. The results show that the calculated time-averaged constraint force $\langle\lambda\rangle$ obtained in the quartet multiplicity case (I) increases systematically (see black triangles in Figure 3a), and no electron transfer from the catalyst to the oxidized $\mathrm{NDI}^{+\bullet}$ occurs (Figure $3 \mathrm{~b}$ ) when shortening the constraint distance $d\left(\mathrm{O}_{\mathrm{i}} \leftarrow \mathrm{O}_{\mathrm{ii}}\right)$ (Scheme $2 \mathrm{~b}$ ). This implies that the $\mathrm{O}-\mathrm{O}$ bond formation is thermodynamically unfavorable for this spin alignment. Instead, the doublet state (II) facilitates the formation of this bond in the third catalytic step (see eq 2, where $\mathrm{H}_{2} \mathrm{O}_{\text {sol }}$ represents the solvated attacking water molecule), demonstrating again the significant role of spin alignment in the investigated supramolecular complex. ${ }^{91-93}$ In the following, we then focus only on the $S=1 / 2$ spin state for the third redox couple.

$$
\begin{aligned}
& { }^{2}\left(\left[\mathrm{Ru}^{\mathrm{IV}}=\mathrm{O}\right]^{2+}-\mathrm{NDI}^{+\bullet}\right)+\mathrm{H}_{2} \mathrm{O}_{\text {sol }} \\
& \quad \leftrightarrow{ }^{2}\left(\left[\mathrm{Ru}^{\mathrm{III}}-\mathrm{OOH}\right]^{2+}-\mathrm{NDI}\right)+\mathrm{H}_{\text {sol }}^{+}
\end{aligned}
$$

The spin density for the reactant (doublet) in route (1) (eq 2) shows as expected two unpaired electrons localized on the catalyst and one unpaired electron localized on the $\mathrm{NDI}^{+} \bullet$ with an antiparallel spin (Figure 3c, inset (left)).

According to the results of our AIMD simulations, the third catalytic water oxidation step can be described by three features: (1) attacking water rearrangement to reach a favorable orientation with respect to the oxygen ligand; (2) electron transfer from the WOC to the photoinduced hole on the oxidized $\mathrm{NDI}^{+\bullet}$; and (3) proton transfer and diffusion into the solvent bulk.

\subsubsection{Attacking Water Rearrangement and Electron} Transfer. After equilibration of the system during the free $\mathrm{MD}$ simulation, one water molecule in the vicinity of the ${ }^{3}\left(\left[\mathrm{Ru}^{\mathrm{IV}}=\mathrm{O}\right]^{2+}\right)$ group is selected as the attacking water molecule during the constrained $\mathrm{MD}$ trajectories (Figure $\mathrm{S} 10 \mathrm{a})$. A few representative configurations with constrained $d\left(\mathrm{O}_{\mathrm{i}} \leftarrow \mathrm{O}_{\mathrm{ii}}\right)$ values ranging from 3.0 to $2.1 \AA$ are shown in Figure $\mathrm{S} 10 \mathrm{~b}-\mathrm{f}$. The attacking water molecule has initially one hydrogen atom pointing to the oxygen ligand $\left(\mathrm{O}_{\mathrm{i}}\right)$ of the ${ }^{3}\left(\left[\mathrm{Ru}^{\mathrm{IV}}=\mathrm{O}\right]^{2+}\right)$ center $\left(2.5 \AA<d\left(\mathrm{O}_{\mathrm{i}} \leftarrow \mathrm{O}_{\mathrm{ii}}\right)<3.0 \AA\right)$. When the constrained $d\left(\mathrm{O}_{\mathrm{i}} \leftarrow \mathrm{O}_{\mathrm{ii}}\right)$ is shortened to $2.3 \AA$, the attacking water molecule starts to rotate and reaches a state with its oxygen atom $\left(\mathrm{O}_{\mathrm{ii}}\right)$ now pointing toward the oxygen ligand $\left(\mathrm{O}_{\mathrm{i}}\right)$, preparing for the $\mathrm{O}-\mathrm{O}$ bond formation. Moreover, the attacking water molecule forms strong hydrogen bonds with neighboring water molecules at the beginning of the $2.0 \AA$ simulation (Figure S11). This hydrogen-bonding network not only stabilizes the configuration of the attacking water molecule but also predisposes the system for the subsequent proton diffusion process.

The integrated spin density localized on the catalyst along the constrained MD trajectories is reported in Figure $3 \mathrm{c}$ to clarify the electron dynamics during this catalytic step. During the initial water attack stage $\left(2.5 \AA<d\left(\mathrm{O}_{\mathrm{i}} \leftarrow \mathrm{O}_{\mathrm{ii}}\right)<3.0 \AA\right)$, the spin density localized on the catalyst fluctuates around an average value of $\sim-1.8$, corresponding to the expected triplet state of this catalyst intermediate, whereas one unpaired electron with antiparallel spin is localized on the oxidized $\mathrm{NDI}^{+\bullet}$ (Figure 3c, inset (left)). The shortening of $d\left(\mathrm{O}_{\mathrm{i}} \leftarrow \mathrm{O}_{\mathrm{ii}}\right)$ from 2.5 to $2.0 \AA$ induces the electron transfer from the 
catalyst to the oxidized $\mathrm{NDI}^{+\bullet}$ dye, which is facilitated by the rearrangement of the attacking water. The spin density localized on the catalyst during the constrained $2.0 \AA$ simulation fluctuates around an average of -1 , indicating the accomplishment of the electron transfer and the filling of the photoinduced hole on the $\mathrm{NDI}^{+}$dye. No proton transfer occurs during the constrained $2.0 \AA$ dynamics, even though the electron transfer has already taken place. The $\mathrm{H}_{\mathrm{ii}}-\mathrm{O}_{\mathrm{ii}}$ bond (Scheme $2 \mathrm{~b}$ ) is however slightly weakened with a maximum distance of $\sim 1.1 \AA$ (Figure S12). When we further shorten the constrained $d\left(\mathrm{O}_{\mathrm{i}} \leftarrow \mathrm{O}_{\mathrm{ii}}\right)$ from 1.9 to $1.5 \AA$, proton transfer takes place (see the next section) and the spin density on the catalyst reaches a stable value of -1 , indicating that only one unpaired electron is finally left on the catalyst (Figure 3c, inset (right)) and no back-reaction occurs even when the constraint is released (FMD).

3.2.2. Proton Diffusion. Based on the behavior of the $\mathrm{H}_{\mathrm{ii}}-$ $\mathrm{O}_{\mathrm{ii}}$ bond during the constrained 2.0 $\AA \mathrm{MD}$ simulation, the electron transfer precedes the proton diffusion process. Further analysis of the constrained MD trajectories shows that one attempt of proton transfer followed by a fast back-reaction is observed during the constrained MD with $d\left(\mathrm{O}_{\mathrm{i}} \leftarrow \mathrm{O}_{\mathrm{ii}}\right)=1.9 \AA$ (Figure S12). The $\mathrm{H}_{\mathrm{ii}}$ proton is finally released from $\mathrm{O}_{\mathrm{ii}}$ of the attacking water molecule during the constrained $1.8 \AA$ dynamics. Figure 4 shows how the formation of a "chain" of hydrogen-bonded water molecules (Figure 4a) provides a channel for rapid proton diffusion from $\mathrm{O}_{\mathrm{ii}}$ of the attacking water molecule into the solvent bulk via a Grotthuss-type mechanism. In Figure $4 \mathrm{~b}$, we trace the $d(\mathrm{H}-\mathrm{O})$ distances involved in the bond-breaking and -formation process leading to the proton diffusion.
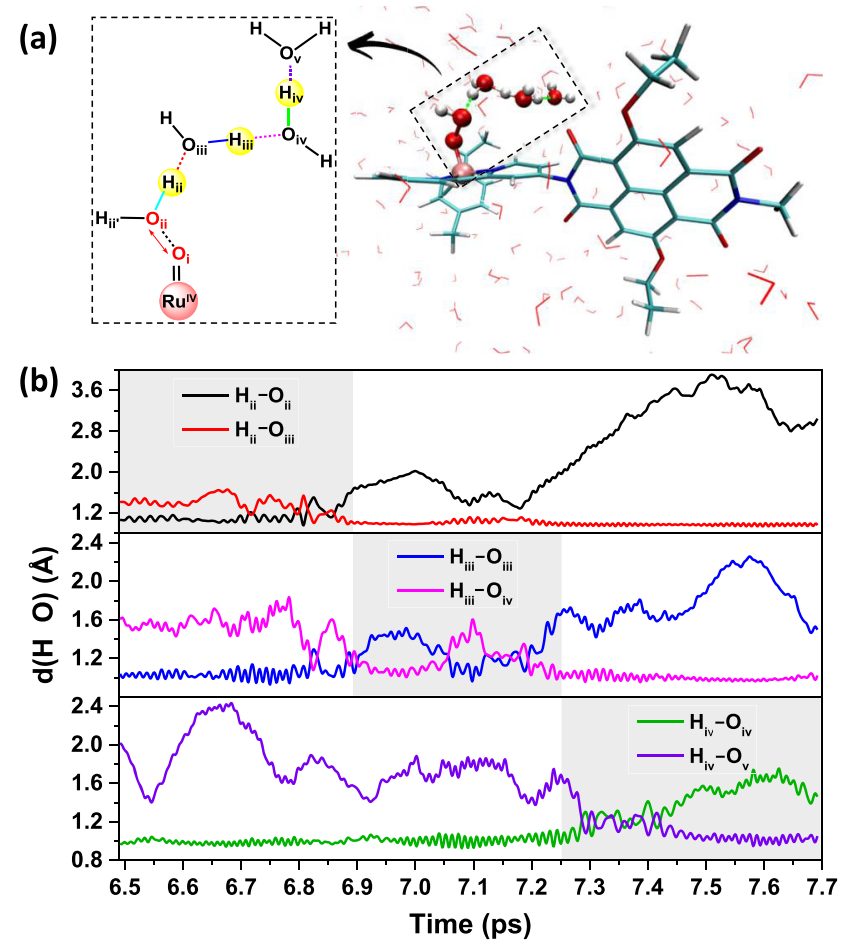

Figure 4. (a) Water molecules involved in the proton diffusion path from oxygen $\mathrm{O}_{\mathrm{ii}}$ into the solvent bulk. (b) Time evolution of the $d(\mathrm{H}-\mathrm{O})$ distances contributing to the proton diffusion along the constrained MD trajectory corresponding to the constraint value $d\left(\mathrm{O}_{\mathrm{i}}\right.$ $\left.\leftarrow \mathrm{O}_{\mathrm{ii}}\right)=1.8 \AA$. The time range is consistent with that in Figure $3 \mathrm{c}$.
The time evolution of $d\left(\mathrm{H}_{\mathrm{ii}}-\mathrm{O}_{\mathrm{ii}}\right)$ and $d\left(\mathrm{H}_{\mathrm{ii}}-\mathrm{O}_{\mathrm{iii}}\right)$ (Figure $4 \mathrm{~b}$, top) shows that the $\mathrm{H}_{\mathrm{ii}}$ proton does several attempts between 6.7 and 6.9 ps before eventually jumping from oxygen $\mathrm{O}_{\mathrm{ii}}$ to $\mathrm{O}_{\mathrm{iii}}$. Almost simultaneous to the $\mathrm{H}_{\mathrm{ii}}$ proton transfer from $\mathrm{O}_{\mathrm{ii}}$ to $\mathrm{O}_{\mathrm{iii}}$, the $\mathrm{H}_{\mathrm{iii}}$ proton makes a first spontaneous jump from oxygen $\mathrm{O}_{\mathrm{iii}}$ to $\mathrm{O}_{\mathrm{iv}}$, as the acceptance of the $\mathrm{H}_{\mathrm{ii}}$ proton by the oxygen $\mathrm{O}_{\mathrm{iii}}$ weakens the $\mathrm{H}_{\mathrm{iii}}-\mathrm{O}_{\mathrm{iii}}$ bond (Figure $4 \mathrm{~b}$, middle, $\sim 6.85 \mathrm{ps}$ ). The $\mathrm{H}_{\mathrm{iii}}$ proton appears to be shared by the oxygen $\mathrm{O}_{\mathrm{iii}}$ and $\mathrm{O}_{\mathrm{iv}}$ until it is fully transferred to $\mathrm{O}_{\mathrm{iv}}$ (Figure $4 \mathrm{~b}$, middle, $\sim 7.2 \mathrm{ps}$ ). Soon after, the $\mathrm{H}_{\mathrm{iv}}$ proton is successfully transferred from $\mathrm{O}_{\text {iv }}$ to $\mathrm{O}_{\mathrm{v}}$ (Figure $4 \mathrm{~b}$, bottom, $\sim 7.4 \mathrm{ps}$ ). These results provide strong evidence that the nature of this proton diffusion process is well described by the Grotthuss mechanism. ${ }^{82-85}$ The excess proton diffuses further into the solvent bulk during the following constrained MD simulations with fixed $d\left(\mathrm{O}_{\mathrm{i}} \leftarrow \mathrm{O}_{\mathrm{ii}}\right)$ from 1.7 to $1.5 \AA$. More importantly, no back-transfer of proton is observed even after removing the constraint at the end of $1.5 \AA$ simulation, showing the stability of the newly formed hydroperoxo intermediate ${ }^{2}\left(\left[\mathrm{Ru}^{\mathrm{III}}-\right.\right.$ $\mathrm{OOH}]^{2+}-\mathrm{NDI}$ ) in the $S=1 / 2$ state. In the free MD trajectory, the $d\left(\mathrm{O}_{\mathrm{i}}-\mathrm{O}_{\mathrm{ii}}\right)$ fluctuates around an average value of $1.32 \AA$, indicating the formation of a strong $\mathrm{O}-\mathrm{O}$ bond after the proton diffusion process. For comparison, the $\mathrm{O}-\mathrm{O}$ bond length in molecular hydrogen peroxide is $1.47 \AA .^{56}$ The relatively short $\mathrm{O}-\mathrm{O}$ bond can be further ascribed to the weakened $\mathrm{O}_{\mathrm{ii}}-\mathrm{H}_{\mathrm{ii}}$ bond (Figure $4 \mathrm{a}$ ), which will be discussed in detail in the next section.

The time-averaged mean forces associated with the applied constraint are collected in Figure 3a (red squares), leading to the free energy profile shown in Figure 5 by thermodynamic

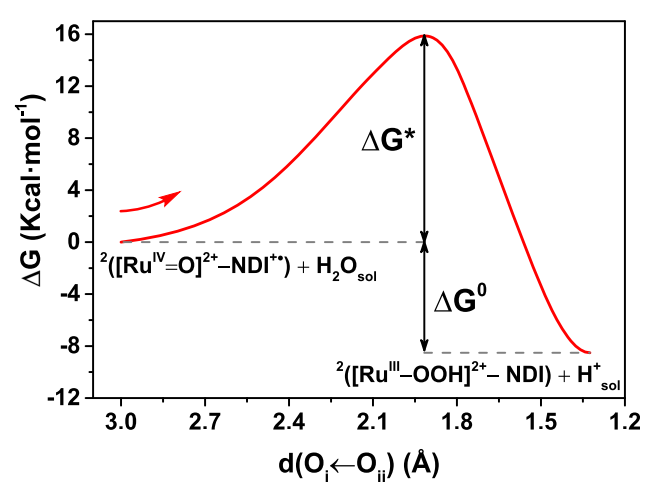

Figure 5. Free energy profile along the reaction coordinate $d\left(\mathrm{O}_{\mathrm{i}} \leftarrow\right.$ $\left.\mathrm{O}_{\mathrm{ii}}\right)$ computed by thermodynamic integration. All of the constrained MD simulations are performed with doublet multiplicity, corresponding to having two unpaired $\alpha$ electrons on the Ru-based catalyst and one $\beta$ electron on the oxidized $\mathrm{NDI}^{+}$. The initial and final intermediates are also indicated.

integration. As expected, the $\mathrm{O}-\mathrm{O}$ bond formation step presents a considerably higher activation energy barrier $\Delta G^{*} \approx$ $15.9 \mathrm{kcal} \mathrm{mol}^{-1}(\sim 0.69 \mathrm{eV})$ compared with the previous two catalytic steps (Table 1). This step is indeed normally considered the thermodynamic bottleneck of the water splitting process in mononuclear WOC. ${ }^{21}$ In addition to the involvement of $\mathrm{O}-\mathrm{O}$ bond formation, such a high reaction barrier can be partly attributed to the low-energy starting point since the second intermediate ${ }^{3}\left(\left[\mathrm{Ru}^{\mathrm{IV}}=\mathrm{O}\right]^{2+}-\mathrm{NDI}\right)$ is quite stable in the water solvent. ${ }^{44}$ However, also this catalytic step leading to the intermediate ${ }^{2}\left(\left[\mathrm{Ru}^{\mathrm{III}}-\mathrm{OOH}\right]^{2+}-\mathrm{NDI}\right)$ is found to be exothermic after photooxidation with a predicted driving 
force $\Delta G^{0} \approx-8.5 \mathrm{kcal} \mathrm{mol}^{-1}(\sim 0.37 \mathrm{eV})$ (Figure 5). In spite of the considerably high activation energy barrier, the oxidized $\mathrm{NDI}^{+\bullet}$ dye is still capable of driving the formation of the $\mathrm{O}-\mathrm{O}$ bond, provided that antiparallel spin alignment is achieved. According to the transition state theory, ${ }^{94-97}$ the reaction rate $(k)$ is determined by the activation energy barrier $\left(\Delta G^{*}\right)$

$$
k=\frac{k_{\mathrm{B}} T}{h} \mathrm{e}^{-\Delta G^{*} / R T}
$$

where $k_{\mathrm{B}}, h, R$, and $T$ are the Boltzmann constant, the Planck constant, the universal gas constant, and the thermodynamic temperature, respectively. The calculated rates of the first three catalytic steps along route (1) (as well as route (2), for comparison) are listed in Table 1 . The first two catalytic steps are very fast with the rates of $\sim 3.6 \times 10^{11}$ and $\sim 1.3 \times$ $10^{11} \mathrm{~s}^{-1}$, respectively, whereas the third step is around 10 orders of magnitude slower. Although the third step involving the $\mathrm{O}-\mathrm{O}$ bond formation with a rate of $15.7 \mathrm{~s}^{-1}$ is unquestionably the rate-limiting step, the specific WOC coupled with the NDI dye shows a competitive rate compared with some typical Ru-based mononuclear WOCs. ${ }^{21}$ Due to the slow rate of this step, electron recombination from the semiconductor to the NDI might compete with the electron transfer from the WOC to the dye, therefore reducing the efficiency of the whole process. ${ }^{98,99}$

Additionally, the third step along route (2) (Scheme 1) has been also investigated, and the results are reported in Figure S13. The computed free energy profile shows that this route is still thermodynamically viable, leading to the same product intermediate ${ }^{2}\left(\left[\mathrm{Ru}^{\mathrm{III}}-\mathrm{OOH}\right]^{2+}-\mathrm{NDI}\right)$ in the $S=1 / 2$ state as for route (1) (Scheme 1 and Figure S14). However, the starting intermediate ${ }^{1}\left(\left[\mathrm{Ru}^{\mathrm{IV}}=\mathrm{O}\right]^{2+}-\mathrm{NDI}\right)$ before photooxidation turned out to be much higher in energy than ${ }^{3}\left(\left[\mathrm{Ru}^{\mathrm{IV}}=\right.\right.$ $\mathrm{O}^{2+}$-NDI) (Figure S8, Tables S3 and S4).

3.3. Fourth Catalytic Water Oxidation Step. In this section, we show that the NDI dye is definitely able to drive the subsequent fourth catalytic step. This is already evident by analyzing the free $\mathrm{MD}$ equilibration run carried out for $0.36 \mathrm{ps}$ at the end of the third catalytic step, after having removed the excess proton from the simulation box. This MD trajectory shows that the $\mathrm{H}_{\mathrm{ii}}$ proton of the hydroperoxo ligand is very weakly bound and essentially shared with the oxygen $\mathrm{O}_{\mathrm{iii}}$ of a hydrogen-bonded water (Scheme 2c), which is reflected in the temporary formation of the first $\mathrm{H}_{3} \mathrm{O}^{+}$at the very beginning of the free MD simulation (Figure 6, middle). In Figure 6 (top), the integrated spin density localized on the catalyst is also reported. Before photooxidation (dashed line in Figure 6), a value of -1 is found consistent with the doublet state of the catalyst. Thereafter, the oxidized intermediate ${ }^{3}\left(\left[\mathrm{Ru}^{\mathrm{III}}-\right.\right.$ $\left.\mathrm{OOH}]^{2+}-\mathrm{NDI}^{+\bullet}\right)$ is formed by removing an electron from the simulation box. A sharp increase of the spin density localized on the catalyst is then observed after photooxidation, indicating an almost instantaneous electron transfer process from the catalyst to the oxidized $\mathrm{NDI}^{+\bullet}$ dye and the generation of a second unpaired electron leading to a triplet state on the catalyst. In Figure S15, we show how the spin density rapidly moves from the oxidized $\mathrm{NDI}^{+}$dye to the $\mathrm{Ru}$-based catalyst along the trajectory. At the same time, the $\mathrm{H}_{\mathrm{ii}}$ proton is rapidly released by the $\mathrm{O}_{\mathrm{ii}}$ atom and transferred to the neighboring water molecules (Figure 6, middle). This very fast PCET process (only $\sim 50 \mathrm{fs}$ after photooxidation of the NDI dye) leads to the final catalytic intermediate ${ }^{3}\left(\left[\mathrm{Ru}^{\mathrm{II}}-\mathrm{OO}\right]^{2+}-\mathrm{NDI}\right)$ (eq 4). This free AIMD simulation demonstrates that the

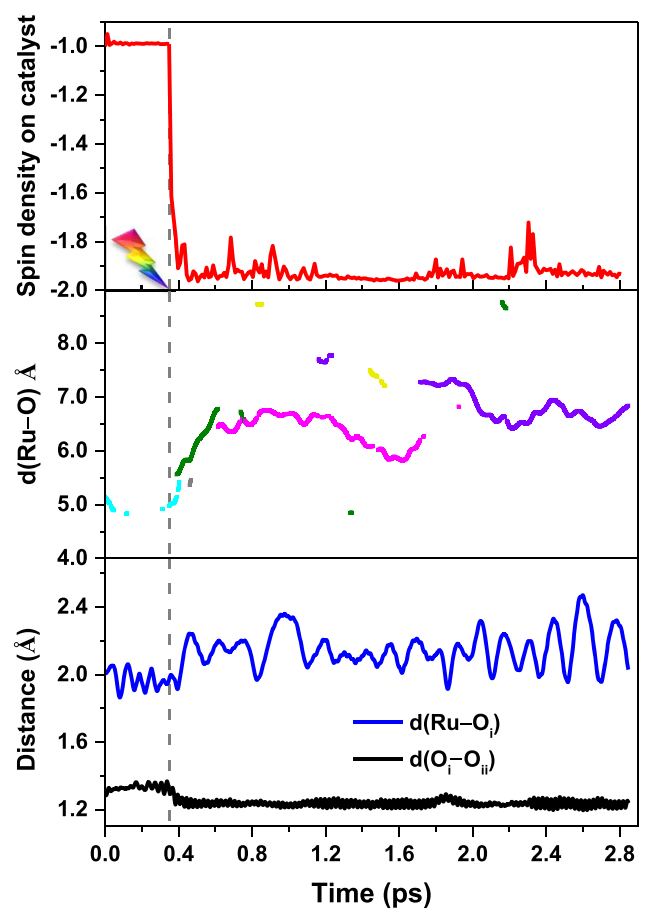

Figure 6. (Top) Spin density integrated over half of the simulation box including the catalyst before and after the photoinduced electron injection, which is mimicked by removing one electron from the system at 0.36 ps to generate an oxidized ${ }^{3}\left(\left[\mathrm{Ru}^{\mathrm{III}}-\mathrm{OOH}\right]^{2+}-\mathrm{NDI}^{+\bullet}\right)$ (indicated by the gray dotted line). (Middle) Distance between Ru and $\mathrm{H}_{3} \mathrm{O}^{+}$measured for the free MD simulations. According to the simulations, the proton primarily bonds to four oxygens (cyan, dark green, magenta, and purple). (Bottom) Time evolution of the geometrical parameters $d\left(\mathrm{Ru}-\mathrm{O}_{\mathrm{i}}\right)$ (blue line) and $d\left(\mathrm{O}_{\mathrm{i}}-\mathrm{O}_{\mathrm{ii}}\right)$ (black line) along the free $\mathrm{MD}$ trajectory (see labeling in Scheme $2 \mathrm{c}$ ).

fourth PCET catalytic water oxidation step occurs without any significant activation energy barrier. Similar electron and nuclear dynamics are observed along route (2) for this catalytic step, which ends up with a less stable intermediate ${ }^{1}\left(\left[\mathrm{Ru}^{\mathrm{II}}-\right.\right.$ $\mathrm{OO}]^{2+}-\mathrm{NDI}$ ) (see more details in Figures S16 and S17, Tables S4 and S5). This is consistent with the $\mathrm{O}_{2}$ ligand being more stable in the $S=1$ state.

$$
\begin{aligned}
& { }^{3}\left(\left[\mathrm{Ru}^{\mathrm{III}}-\mathrm{OOH}\right]^{2+}-\mathrm{NDI}^{+\bullet}\right) \\
& \quad \leftrightarrow{ }^{3}\left(\left[\mathrm{Ru}^{\mathrm{II}}-\mathrm{OO}\right]^{2+}-\mathrm{NDI}\right)+\mathrm{H}_{\text {sol }}^{+}
\end{aligned}
$$

After the proton transfer, the distance between $\mathrm{O}_{\mathrm{i}}$ and $\mathrm{O}_{\mathrm{ii}}$ atoms shortens to an average value of $\sim 1.24 \AA$ (black line in Figure 6, bottom), confirming the formation of the $\mathrm{O}=\mathrm{O}$ bond (for comparison, the $\mathrm{O}=\mathrm{O}$ bond length in molecular $\mathrm{O}_{2}$ is $1.21 \AA$ ). The final spin density mainly localizes on the two oxygen atoms $\left(\mathrm{O}_{\mathrm{i}}\right.$ and $\left.\mathrm{O}_{\mathrm{ii}}\right)$, providing strong evidence for the generation of the triplet molecular $\mathrm{O}_{2}$ product (Figure S15). As a result, the $\mathrm{Ru}-\mathrm{O}_{\mathrm{i}}$ bond is considerably weakened (blue line in Figure 6, bottom), which indicates that the generated molecular $\mathrm{O}_{2}$ can be easily exchanged with a water molecule in solution, thus regenerating the initial WOC state.

By analyzing the nuclear trajectory during the electron transfer process, we can observe a clear change in the dihedral angle $(\angle \mathrm{C} 1-\mathrm{N} 1-\mathrm{C} 2-\mathrm{C} 3$; see Scheme 1$)$ around the $\mathrm{C}-\mathrm{N}$ bond connecting the NDI and the Ru catalyst from an average value of $\sim 60$ to $90-100^{\circ}$. In Figure S18, the evolution of this angle together with the spin density evolution is reported, suggesting a correlation between this torsional motion and the 
electron dynamics. Coherence in the electron and nuclear motion has been suggested to play a role in electron transfer processes in both natural and artificial systems. ${ }^{54,100}$ It might be interesting to further analyze the coupling between electronic and nuclear motion with quantum-classical simulations.

\section{CONCLUSIONS}

The whole photocatalytic water splitting cycle performed by the WOC-dye supramolecular complex $\left[\mathrm{Ru}^{\mathrm{II}}\left(\mathrm{H}_{2} \mathrm{O}\right)\right]^{2+}-\mathrm{NDI}$ in water solution has been systematically explored by means of DFT-based AIMD simulations at room temperature. The coupled electron and proton dynamics together with the solvent rearrangement are followed during the cycle, elucidating the catalytic mechanism of the four consecutive water oxidation steps.

The first three catalytic water oxidation steps are all exothermic with negative driving force $\Delta G^{0}$ after photooxidation of the NDI dye. The electron transfer from the catalyst to the oxidized dye always precedes the proton diffusion into the solvent bulk. The first and second PCET catalytic steps present a similar small activation energy barrier on the order of a few $k_{\mathrm{B}} T$ at room temperature. The second PCET step has a larger driving force compared with the first, suggesting a much more stable product intermediate ${ }^{3}\left(\left[\mathrm{Ru}^{\mathrm{IV}}=\right.\right.$ $\left.\mathrm{O}]^{2+}-\mathrm{NDI}\right)$. The third PCET catalytic step involving the O$\mathrm{O}$ bond formation with a second attacking water has a considerably higher activation energy barrier. This is the ratelimiting step where recombination processes from the semiconductor into the oxidized dye might indeed reduce the quantum efficiency of the whole process. One possible strategy to mitigate this issue is to add a molecular rectifier bridge between the dye and the semiconductor surface. ${ }^{54}$ It is found that antiparallel spin alignment of unpaired electrons on the WOC and dye is essential for the occurrence of $\mathrm{O}-\mathrm{O}$ bond formation. The rearrangement of solvent water molecules and formation of a hydrogen-bonding network during $\mathrm{MD}$ simulations further facilitate the subsequent proton diffusion process. Interestingly, the fourth PCET step occurs immediately after the photooxidation of the NDI dye without any energy barrier, leading to the final intermediate with the $\mathrm{O}_{2}$ ligand. All these results demonstrate that the selected NDI dye is a promising dye sensitizer to integrate in a DS-PEC device: it is able to perform fast electron injection into $\mathrm{TiO}_{2}$ upon visible light absorption, and in its oxidized form it can drive the whole photocatalytic water splitting cycle when properly coupled to the Ru-based catalyst. Considering that the NDI is capable of extracting electrons from the catalyst over the whole cycle, PCET conversion mediated by quantum overlap and vibrationally assisted is a mechanism that may be difficult to suppress, which works to the advantage of smooth catalysis. ${ }^{101,102}$

Further progress aimed at lowering the activation energy barrier of the third PCET catalytic step can be achieved by introducing extra proton acceptors ${ }^{103-108}$ near the active site and/or by assembling the catalyst near an ion-exchange membrane ${ }^{109-113}$ between the anode and cathode chambers, which would create a favorable environment to facilitate proton release and transport through the membrane.

\section{ASSOCIATED CONTENT}

\section{Supporting Information}

The Supporting Information is available free of charge on the ACS Publications website at DOI: 10.1021/acs.jpcc.9b06401.

Static DFT calculations of all intermediates along the catalytic pathway, schematic diagram of DS-PEC and WOC-dye supramolecular complex for solar-driven water oxidation, additional results concerning specific catalytic steps and different spin states, summary of the free energy profiles for the whole catalytic cycle, time evolution of dihedral angle $\angle \mathrm{C} 1-\mathrm{N} 1-\mathrm{C} 2-\mathrm{C} 3$ along the $\mathrm{MD}$ trajectories (PDF)

\section{AUTHOR INFORMATION}

\section{Corresponding Author}

*E-mail: f.buda@lic.leidenuniv.nl.

ORCID

Jessica M. de Ruiter: 0000-0001-8984-2439

Francesco Buda: 0000-0002-7157-7654

\section{Author Contributions}

The manuscript was written through contributions of all authors. All authors have given approval to the final version of the manuscript.

Notes

The authors declare no competing financial interest.

\section{ACKNOWLEDGMENTS}

We acknowledge the use of supercomputer facilities at SURFsara sponsored by NWO Physical Sciences, with financial support from the Netherlands Organization for Scientific Research (NWO). This research was supported by the NWO Solar to Products program, project number 733.000.007. Y.S. acknowledges financial support from the China Scholarship Council (201606450019).

\section{REFERENCES}

(1) Dresselhaus, M. S.; Thomas, I. L. Alternative energy technologies. Nature 2001, 414, 332-337.

(2) Chynoweth, D. P.; Owens, J. M.; Legrand, R. Renewable methane from anaerobic digestion of biomass. Renewable Energy 2001, $22,1-8$.

(3) Lewis, N. S. Toward cost-effective solar energy use. Science 2007, $315,798-801$.

(4) Nocera, D. G. The artificial leaf. Acc. Chem. Res. 2012, 45, 767776.

(5) Gust, D.; Moore, T. A.; Moore, A. L. Solar fuels via artificial photosynthesis. Acc. Chem. Res. 2009, 42, 1890-1898.

(6) Zaharieva, I.; Wichmann, J. M.; Dau, H. Thermodynamic limitations of photosynthetic water oxidation at high proton concentrations. J. Biol. Chem. 2011, 286, 18222-18228.

(7) Tachibana, Y.; Vayssieres, L.; Durrant, J. R. Artificial photosynthesis for solar water-splitting. Nat. Photonics 2012, 6, 511-518.

(8) Dau, H.; Zaharieva, I.; Haumann, M. Recent developments in research on water oxidation by photosystem II. Curr. Opin. Chem. Biol. 2012, 16, 3-10.

(9) Jafari, T.; Moharreri, E.; Amin, A.; Miao, R.; Song, W.; Suib, S. Photocatalytic water splitting-The untamed dream: a review of recent advances. Molecules 2016, 21, 900.

(10) Kim, W.; Edri, E.; Frei, H. Hierarchical inorganic assemblies for artificial photosynthesis. Acc. Chem. Res. 2016, 49, 1634-1645.

(11) Xiang, C.; Weber, A. Z.; Ardo, S.; Berger, A.; Chen, Y.; Coridan, R.; Fountaine, K. T.; Haussener, S.; Hu, S.; Liu, R.; et al. 
Modeling, simulation, and implementation of solar-driven watersplitting devices. Angew. Chem., Int. Ed. 2016, 55, 12974-12988.

(12) Turan, B.; Becker, J.-P.; Urbain, F.; Finger, F.; Rau, U.; Haas, S. Upscaling of integrated photoelectrochemical water-splitting devices to large areas. Nat. Commun. 2016, 7, No. 12681.

(13) Grätzel, M. Photoelectrochemical cells. Nature 2001, 414, 338-344.

(14) Liu, C.; Colón, B. C.; Ziesack, M.; Silver, P. A.; Nocera, D. G. Water splitting-biosynthetic system with $\mathrm{CO}_{2}$ reduction efficiencies exceeding photosynthesis. Science 2016, 352, 1210-1213.

(15) Haas, T.; Krause, R.; Weber, R.; Demler, M.; Schmid, G. Technical photosynthesis involving $\mathrm{CO}_{2}$ electrolysis and fermentation. Nat. Catal. 2018, 1, 32-39.

(16) Inoue, H.; Shimada, T.; Kou, Y.; Nabetani, Y.; Masui, D.; Takagi, S.; Tachibana, H. The water oxidation bottleneck in artificial photosynthesis: how can we get through it? An alternative route involving a two-electron process. ChemSusChem 2011, 4, 173-179.

(17) Yu, Z.; Li, F.; Sun, L. Recent advances in dye-sensitized photoelectrochemical cells for solar hydrogen production based on molecular components. Energy Environ. Sci. 2015, 8, 760-775.

(18) Peerakiatkhajohn, P.; Yun, J.-H.; Wang, S.; Wang, L. Review of recent progress in unassisted photoelectrochemical water splitting: from material modification to configuration design. J. Photonics Energy 2017, 7, No. 012006.

(19) Ding, X.; Gao, Y.; Ye, L.; Zhang, L.; Sun, L. Insights into electrolyte effects on photoactivities of dye-sensitized photoelectrochemical cells for water splitting. ChemSusChem 2015, 8, 39923995.

(20) Moniz, S. J. A.; Shevlin, S. A.; Martin, D. J.; Guo, Z.-X.; Tang, J. Visible-light driven heterojunction photocatalysts for water splitting-a critical review. Energy Environ. Sci. 2015, 8, 731-759.

(21) Hetterscheid, D. G. H.; Reek, J. N. H. Mononuclear water oxidation catalysts. Angew. Chem., Int. Ed. 2012, 51, 9740-9747.

(22) Concepcion, J. J.; Jurss, J. W.; Brennaman, M. K.; Hoertz, P. G.; Patrocinio, A. O. T.; Murakami Iha, N. Y.; Templeton, J. L.; Meyer, T. J. Making oxygen with ruthenium complexes. Acc. Chem. Res. 2009, 42, 1954-1965.

(23) Duan, L.; Xu, Y.; Gorlov, M.; Tong, L.; Andersson, S.; Sun, L. Chemical and photochemical water oxidation catalyzed by mononuclear ruthenium complexes with a negatively charged tridentate ligand. Chem. - Eur. J. 2010, 16, 4659-4668.

(24) Prévot, M. S.; Sivula, K. Photoelectrochemical tandem cells for solar water splitting. J. Phys. Chem. C 2013, 117, 17879-17893.

(25) Swierk, J. R.; Mallouk, T. E. Design and development of photoanodes for water-splitting dye-sensitized photoelectrochemical cells. Chem. Soc. Rev. 2013, 42, 2357-2387.

(26) Luo, J.; Im, J.-H.; Mayer, M. T.; Schreier, M.; Nazeeruddin, M. K.; Park, N.-G.; Tilley, S. D.; Fan, H. J.; Grätzel, M. Water photolysis at $12.3 \%$ efficiency via perovskite photovoltaics and earth-abundant catalysts. Science 2014, 345, 1593-1596.

(27) Liu, J.; Liu, Y.; Liu, N.; Han, Y.; Zhang, X.; Huang, H.; Lifshitz, Y.; Lee, S.-T.; Zhong, J.; Kang, Z. Metal-free efficient photocatalyst for stable visible water splitting via a two-electron pathway. Science 2015, 347, 970-974.

(28) Swierk, J. R.; Méndez-Hernández, D. D.; McCool, N. S.; Liddell, P.; Terazono, Y.; Pahk, I.; Tomlin, J. J.; Oster, N. V.; Moore, T. A.; Moore, A. L.; et al. Metal-free organic sensitizers for use in water-splitting dye-sensitized photoelectrochemical cells. Proc. Natl. Acad. Sci. U.S.A. 2015, 112, 1681-1686.

(29) Verlage, E.; Hu, S.; Liu, R.; Jones, R. J. R.; Sun, K.; Xiang, C.; Lewis, N. S.; Atwater, H. A. A stabilized, intrinsically safe, $10 \%$ efficient, solar-driven water-splitting cell incorporating earth-abundant electrocatalysts with steady-state $\mathrm{pH}$ gradients and product separation enabled by a bipolar membrane. Energy Environ. Sci. 2015, 8, 31663172 .

(30) de Respinis, M.; Joya, K. S.; De Groot, H. J. M.; D’Souza, F.; Smith, W. A.; van de Krol, R.; Dam, B. Oxynitrogenography: controlled synthesis of single-phase tantalum oxynitride photoabsorbers. J. Phys. Chem. C 2015, 119, 7275-7281.
(31) Ding, X.; Zhang, L.; Wang, Y.; Liu, A.; Gao, Y. Design of photoanode-based dye-sensitized photoelectrochemical cells assembling with transition metal complexes for visible light-induced water splitting. Coord. Chem. Rev. 2018, 357, 130-143.

(32) Brennaman, M. K.; Dillon, R. J.; Alibabaei, L.; Gish, M. K.; Dares, C. J.; Ashford, D. L.; House, R. L.; Meyer, G. J.; Papanikolas, J. M.; Meyer, T. J. Finding the way to solar fuels with dye-sensitized photoelectrosynthesis cells. J. Am. Chem. Soc. 2016, 138, 1308513102.

(33) Dau, H.; Limberg, C.; Reier, T.; Risch, M.; Roggan, S.; Strasser, P. The mechanism of water oxidation: from electrolysis via homogeneous to biological catalysis. ChemCatChem 2010, 2, 724761.

(34) Hughes, T. F.; Friesner, R. A. Systematic investigation of the catalytic cycle of a single site ruthenium oxygen evolving complex using density functional theory. J. Phys. Chem. B 2011, 115, 92809289.

(35) Akimov, A. V.; Neukirch, A. J.; Prezhdo, O. V. Theoretical insights into photoinduced charge transfer and catalysis at oxide interfaces. Chem. Rev. 2013, 113, 4496-4565.

(36) McCool, N. S.; Swierk, J. R.; Nemes, C. T.; Saunders, T. P.; Schmuttenmaer, C. A.; Mallouk, T. E. Proton-induced trap states, injection and recombination dynamics in water-splitting dyesensitized photoelectrochemical cells. ACS Appl. Mater. Interfaces 2016, 8, 16727-16735.

(37) Concepcion, J. J.; Tsai, M.-K.; Muckerman, J. T.; Meyer, T. J. Mechanism of water oxidation by single-site ruthenium complex catalysts. J. Am. Chem. Soc. 2010, 132, 1545-1557.

(38) Pastore, M. First Principle Modelling of Materials and Processes in Dye-Sensitized Photoanodes for Solar Energy and Solar Fuels. Computation 2017, 5, 5.

(39) Monti, A.; de Ruiter, J. M.; de Groot, H. J. M.; Buda, F. A dynamic view of proton-coupled electron transfer in photocatalytic water splitting. J. Phys. Chem. C 2016, 120, 23074-23082.

(40) Meyer, T. J.; Huynh, M. H. V.; Thorp, H. H. The possible role of proton-coupled electron transfer (PCET) in water oxidation by photosystem II. Angew. Chem., Int. Ed. 2007, 46, 5284-5304.

(41) Hammes-Schiffer, S. Proton-coupled electron transfer: classification scheme and guide to theoretical methods. Energy Environ. Sci. 2012, 5, 7696-7703.

(42) Hammes-Schiffer, S. Proton-coupled electron transfer: moving together and charging forward. J. Am. Chem. Soc. 2015, 137, 88608871.

(43) Huynh, M. H. V.; Meyer, T. J. Proton-Coupled Electron Transfer. Chem. Rev. 2007, 107, 5004-5064.

(44) de Ruiter, J. M.; Purchase, R. L.; Monti, A.; van der Ham, C. J. M.; Gullo, M. P.; Joya, K. S.; D’Angelantonio, M.; Barbieri, A.; Hetterscheid, D. G. H.; de Groot, H. J. M.; et al. Electrochemical and spectroscopic study of mononuclear ruthenium water oxidation catalysts: a combined experimental and theoretical investigation. ACS Catal. 2016, 6, 7340-7349.

(45) Kishore, R. S. K.; Kel, O.; Banerii, N.; Emery, D.; Bollot, G.; Mareda, J.; Gomez-Casado, A.; Jonkheijm, P.; Huskens, J.; Maroni, P.; et al. Ordered and oriented supramolecular $\mathrm{n} / \mathrm{p}$-heterojunction surface architectures: completion of the primary color collection. $J$. Am. Chem. Soc. 2009, 131, 11106-11116.

(46) Sakai, N.; Mareda, J.; Vauthey, E.; Matile, S. Core-substituted naphthalenediimides. Chem. Commun. 2010, 46, 4225-4237.

(47) Diac, A.; Matache, M.; Grosu, I.; Hădade, N. D. Naphthalenediimide-a unique motif in macrocyclic and interlocked supramolecular structures. Adv. Synth. Catal. 2018, 360, 817-845.

(48) Earmme, T.; Hwang, Y.-J.; Murari, N. M.; Subramaniyan, S.; Jenekhe, S. A. All-polymer solar cells with $3.3 \%$ efficiency based on naphthalene diimide-selenophene copolymer acceptor. J. Am. Chem. Soc. 2013, 135, 14960-14963.

(49) Choi, J.; Kim, K.-H.; Yu, H.; Lee, C.; Kang, H.; Song, I.; Kim, Y.; Oh, J. H.; Kim, B. J. Importance of electron transport ability in naphthalene diimide-based polymer acceptors for high-performance, 
additive-free, all-polymer solar cells. Chem. Mater. 2015, 27, 52305237.

(50) Kim, T.; Kim, J.-H.; Kang, T. E.; Lee, C.; Kang, H.; Shin, M.; Wang, C.; Ma, B.; Jeong, U.; Kim, T.-S.; et al. Flexible, highly efficient all-polymer solar cells. Nat. Commun. 2015, 6, No. 8547.

(51) Ambrosio, F.; Martsinovich, N.; Troisi, A. What is the best anchoring group for a dye in a dye-sensitized solar cell? J. Phys. Chem. Lett. 2012, 3, 1531-1535.

(52) Zhang, L.; Cole, J. M. Anchoring groups for dye-sensitized solar cells. ACS Appl. Mater. Interfaces 2015, 7, 3427-3455.

(53) Materna, K. L.; Crabtree, R. H.; Brudvig, G. W. Heterogenized iridium water-oxidation catalyst from a silatrane precursor. Chem. Soc. Rev. 2017, 46, 6099-6110.

(54) Monti, A.; Negre, C. F. A.; Batista, V. S.; Rego, L. G. C.; de Groot, H. J. M.; Buda, F. Crucial role of nuclear dynamics for electron injection in a dye-semiconductor complex. J. Phys. Chem. Lett. 2015, 6, 2393-2398.

(55) Monti, A.; de Groot, H. J. M.; Buda, F. In-silico design of a donor-antenna-acceptor supramolecular complex for photoinduced charge separation. J. Phys. Chem. C 2014, 118, 15600-15609.

(56) Bernasconi, L.; Kazaryan, A.; Belanzoni, P.; Baerends, E. J. Catalytic oxidation of water with high-spin iron(IV)-oxo species: role of the water solvent. ACS Catal. 2017, 7, 4018-4025.

(57) Swart, M.; Ehlers, A. W.; Lammertsma, K. Performance of the OPBE exchange-correlation functional. Mol. Phys. 2004, 102, 24672474.

(58) Carvalho, A. T. P.; Swart, M. Electronic structure investigation and parametrization of biologically relevant iron-sulfur clusters. J. Chem. Inf. Model 2014, 54, 613-620.

(59) Groenhof, A. R.; Ehlers, A. W.; Lammertsma, K. Proton assisted oxygen-oxygen bond splitting in cytochrome P450. J. Am. Chem. Soc. 2007, 129, 6204-6209.

(60) Conradie, J.; Ghosh, A. Bonding in low-coordinate environments: electronic structure of pseudotetrahedral iron-imido complexes. J. Chem. Theory Comput. 2007, 3, 689-702.

(61) Vallés-Pardo, J. L.; Guijt, M. C.; Iannuzzi, M.; Joya, K. S.; de Groot, H. J. M.; Buda, F. Ab initio molecular dynamics study of water oxidation reaction pathways in mono-Ru catalysts. ChemPhysChem 2012, 13, 140-146.

(62) Liao, M.-S.; Watts, J. D.; Huang, M.-J. Electronic structure of some substituted iron(II) porphyrins. are they intermediate or high spin? J. Phys. Chem. A 2007, 111, 5927-5935.

(63) Güell, M.; Luis, J. M.; Siegbahn, P. E. M.; Solà, M. Theoretical study of the hydroxylation of phenols mediated by an end-on bound superoxo-copper(II) complex. J. Biol. Inorg. Chem. 2009, 14, 273285.

(64) Klamt, A. Conductor-like screening model for real solvents: a new approach to the quantitative calculation of solvation phenomena. J. Phys. Chem. A 1995, 99, 2224-2235.

(65) Klamt, A.; Jonas, V. Treatment of the outlying charge in continuum solvation models. J. Chem. Phys. 1996, 105, 9972-9981.

(66) Te Velde, G.; Bickelhaupt, F. M.; Baerends, E. J.; Fonseca Guerra, C.; van Gisbergen, S. J. A.; Snijders, J. G.; Ziegler, T. Chemistry with ADF. J. Comput. Chem. 2001, 22, 931-967.

(67) ADF2017, SCM, Theoretical Chemistry; Vrije Universiteit: Amsterdam, The Netherlands. http://www.scm.com.

(68) Ma, C.; Piccinin, S.; Fabris, S. Reaction mechanisms of water splitting and $\mathrm{H}_{2}$ evolution by a $\mathrm{Ru}(\mathrm{II})$-pincer complex identified with ab Initio metadynamics simulations. ACS Catal. 2012, 2, 1500-1506.

(69) CPMD, http://www.cpmd.org, Copyright IBM Corp., 19902019, Copyright MPI für Festkörperforschung Stuttgart, 1997-2001.

(70) Accelrys Software Inc. Discovery Studio Modeling Environment, Accelrys Software Inc.: San Diego, 2012.

(71) Brooks, B. R.; Bruccoleri, R. E.; Olafson, B. D.; States, D. J.; Swaminathan, S.; Karplus, M. CHARMM: A program for macromolecular energy, minimization, and dynamics calculations. J. Comput. Chem. 1983, 4, 187-217.
(72) Hartwigsen, C.; Goedecker, S.; Hutter, J. Relativistic separable dual-space Gaussian pseudopotentials from $\mathrm{H}$ to Rn. Phys. Rev. B 1998, 58, 3641-3662.

(73) Lin, I. C.; Coutinho-Neto, M. D.; Felsenheimer, C.; von Lilienfeld, O. A.; Tavernelli, I.; Rothlisberger, U. Library of dispersion-corrected atom-centered potentials for generalized gradient approximation functionals: elements $\mathrm{H}, \mathrm{C}, \mathrm{N}, \mathrm{O}, \mathrm{He}, \mathrm{Ne}, \mathrm{Ar}$, and $\mathrm{Kr}$. Phys. Rev. B 2007, 75, No. 205131.

(74) Humphrey, W.; Dalke, A.; Schulten, K. VMD: visual molecular dynamics. J. Mol. Graphics 1996, 14, 33-38.

(75) VMD - Visual Molecular Dynamics. Theoretical Chemistry and Computational Biophysics Group, University Of Illinois: Urbana, 2016.

(76) Ciccotti, G.; Ferrario, M. Blue moon approach to rare events. Mol. Simul. 2004, 30, 787-793.

(77) Ensing, B.; Meijer, E. J.; Blöchl, P. E.; Baerends, E. J. Solvation effects on the $\mathrm{S}_{\mathrm{N}} 2$ Reaction between $\mathrm{CH}_{3} \mathrm{Cl}_{\text {and }} \mathrm{Cl}^{-}$in water. J. Phys. Chem. A 2001, 105, 3300-3310.

(78) Costanzo, F.; Della Valle, R. G. Car-Parrinello MD simulations for the $\mathrm{Na}^{+}-$phenylalanine complex in aqueous solution. J. Phys. Chem. B 2008, 112, 12783-12789.

(79) den Otter, W. K.; Briels, W. J. The calculation of free-energy differences by constrained molecular-dynamics simulations. J. Chem. Phys. 1998, 109, 4139-4146.

(80) Sprik, M.; Ciccotti, G. Free energy from constrained molecular dynamics. J. Chem. Phys. 1998, 109, 7737-7744.

(81) Bernasconi, L.; Baerends, E. J.; Sprik, M. Long-range solvent effects on the orbital interaction mechanism of water acidity enhancement in metal ion solutions: a comparative study of the electronic structure of aqueous $\mathrm{Mg}$ and $\mathrm{Zn}$ dications. J. Phys. Chem. B 2006, 110, 11444-11453.

(82) de Grotthuss, C. J. T. Memoir on the decomposition of water and of the bodies that it holds in solution by means of galvanic electricity. Biochim. Biophys. Acta, Bioenerg. 2006, 1757, 871-875.

(83) Agmon, N. The grotthuss mechanism. Chem. Phys. Lett. 1995, 244, 456-462.

(84) Cukierman, S. Et tu, Grotthuss! and other unfinished stories. Biochim. Biophys. Acta, Bioenerg 2006, 1757, 876-885.

(85) Markovitch, O.; Chen, H.; Izvekov, S.; Paesani, F.; Voth, G. A.; Agmon, N. Special pair dance and partner selection: elementary steps in proton transport in liquid water. J. Phys. Chem. B 2008, 112, 94569466.

(86) Hassanali, A.; Giberti, F.; Cuny, J.; Kühne, T. D.; Parrinello, M. Proton transfer through the water gossamer. Proc. Natl. Acad. Sci. U.S.A. 2013, 110, 13723-13728.

(87) Marx, D.; Chandra, A.; Tuckerman, M. E. Aqueous basic solutions: hydroxide solvation, structural diffusion, and comparison to the hydrated proton. Chem. Rev. 2010, 110, 2174-2216.

(88) Codorniu-Hernández, E.; Kusalik, P. G. Probing the mechanisms of proton transfer in liquid water. Proc. Natl. Acad. Sci. U.S.A. 2013, 110, 13697-13698.

(89) Liang, R.; Li, H.; Swanson, J. M. J.; Voth, G. A. Multiscale simulation reveals a multifaceted mechanism of proton permeation through the influenza A M2 proton channel. Proc. Natl. Acad. Sci. U.S.A. 2014, 111, 9396-9401.

(90) Yang, X.; Hall, M. B. Mechanism of water splitting and oxygen-oxygen bond formation by a mononuclear ruthenium complex. J. Am. Chem. Soc. 2010, 132, 120-130.

(91) Lundberg, M.; Siegbahn, P. E. M. Minimum energy spin crossings for an $\mathrm{O}-\mathrm{O}$ bond formation reaction. Chem. Phys. Lett. 2005, 401, 347-351.

(92) Siegbahn, P. E. M. O-O bond formation in the $\mathrm{S}_{4}$ state of the oxygen-evolving complex in photosystem II. Chem. - Eur. J. 2006, 12, 9217-9227.

(93) Guo, Y.; Li, H.; He, L.-L.; Zhao, D.-X.; Gong, L.-D.; Yang, Z.-Z. The open-cubane oxo-oxyl coupling mechanism dominates photosynthetic oxygen evolution: a comprehensive DFT investigation on $\mathrm{O}-\mathrm{O}$ bond formation in the $\mathrm{S}_{4}$ state. Phys. Chem. Chem. Phys. 2017, 19, 13909-13923. 
(94) Eyring, H. The activated complex in chemical reactions. J. Chem. Phys. 1935, 3, 107-115.

(95) Laidler, K. J.; King, M. C. Development of transition-state theory. J. Phys. Chem. A 1983, 87, 2657-2664.

(96) Pollak, E.; Talkner, P. Reaction rate theory: what it was, where is it today, and where is it going? Chaos 2005, 15, No. 026116.

(97) Solis, B. H.; Hammes-Schiffer, S. Proton-coupled electron transfer in molecular electrocatalysis: theoretical methods and design principles. Inorg. Chem. 2014, 53, 6427-6443.

(98) Gish, M. K.; Lapides, A. M.; Brennaman, M. K.; Templeton, J. L.; Meyer, T. J.; Papanikolas, J. M. Ultrafast recombination dynamics in dye-sensitized $\mathrm{SnO}_{2} / \mathrm{TiO}_{2}$ core/shell films. J. Phys. Chem. Lett. 2016, 7, 5297-5301.

(99) Chou, H.-H.; Yang, C.-H.; Lin, J. T.; Hsu, C.-P. First-principle determination of electronic coupling and prediction of charge recombination rates in dye-sensitized solar cells. J. Phys. Chem. C 2017, 121, 983-992.

(100) Scholes, G. D. Coherence from light harvesting to chemistry. J. Phys. Chem. Lett. 2018, 9, 1568-1572.

(101) Bruno, W. J.; Bialek, W. Vibrationally enhanced tunneling as a mechanism for enzymatic hydrogen transfer. Biophys. J. 1992, 63, 689-699.

(102) Moser, C. C.; Keske, J. M.; Warncke, K.; Farid, R. S.; Dutton, P. L. Nature of biological electron transfer. Nature 1992, 355, 796802.

(103) Chen, Z.; Concepcion, J. J.; Hu, X.; Yang, W.; Hoertz, P. G.; Meyer, T. J. Concerted $\mathrm{O}$ atom-proton transfer in the $\mathrm{O}-\mathrm{O}$ bond forming step in water oxidation. Proc. Natl. Acad. Sci. U.S.A. 2010, 107, 7225-7229.

(104) Hammes-Schiffer, S. Theory of proton-coupled electron transfer in energy conversion processes. Acc. Chem. Res. 2009, 42, $1881-1889$

(105) Shaffer, D. W.; Xie, Y.; Concepcion, J. J. O-O bond formation in ruthenium-catalyzed water oxidation: single-site nucleophilic attack vs. O-O radical coupling. Chem. Soc. Rev. 2017, 46, 6170-6193.

(106) Shaffer, D. W.; Xie, Y.; Szalda, D. J.; Concepcion, J. J. Lability and basicity of bipyridine-carboxylate-phosphonate ligand accelerate single-site water oxidation by ruthenium-based molecular catalysts. J. Am. Chem. Soc. 2017, 139, 15347-15355.

(107) Meyer, T. J.; Sheridan, M. V.; Sherman, B. D. Mechanisms of molecular water oxidation in solution and on oxide surfaces. Chem. Soc. Rev. 2017, 46, 6148-6169.

(108) Coggins, M. K.; Zhang, M. T.; Chen, Z.; Song, N.; Meyer, T. J. Single-site copper(II) water oxidation electrocatalysis: rate enhancements with $\mathrm{HPO}_{4}{ }^{2-}$ as a proton acceptor at $\mathrm{pH}$ 8. Angew. Chem., Int. Ed. 2014, 53, 12226-12230.

(109) Varcoe, J. R.; Atanassov, P.; Dekel, D. R.; Herring, A. M.; Hickner, M. A.; Kohl, P. A.; Kucernak, A. R.; Mustain, W. E.; Nijmeijer, K.; Scott, K.; et al. Anion-exchange membranes in electrochemical energy systems. Energy Environ. Sci. 2014, 7, 31353191.

(110) Ran, J.; Wu, L.; He, Y.; Yang, Z.; Wang, Y.; Jiang, C.; Ge, L.; Bakangura, E.; $\mathrm{Xu}, \mathrm{T}$. Ion exchange membranes: new developments and applications. J. Membr. Sci. 2017, 522, 267-291.

(111) Gu, S.; Gong, K.; Yan, E. Z.; Yan, Y. A multiple ion-exchange membrane design for redox flow batteries. Energy Environ. Sci. 2014, 7, 2986-2998.

(112) He, G.; Li, Z.; Zhao, J.; Wang, S.; Wu, H.; Guiver, M. D.; Jiang, Z. Nanostructured ion-exchange membranes for fuel cells: Recent advances and perspectives. Adv. Mater. 2015, 27, 5280-5295.

(113) Hammarström, L. Accumulative charge separation for solar fuels production: coupling light-induced single electron transfer to multielectron catalysis. Acc. Chem. Res. 2015, 48, 840-850. 